BMC

Genomics

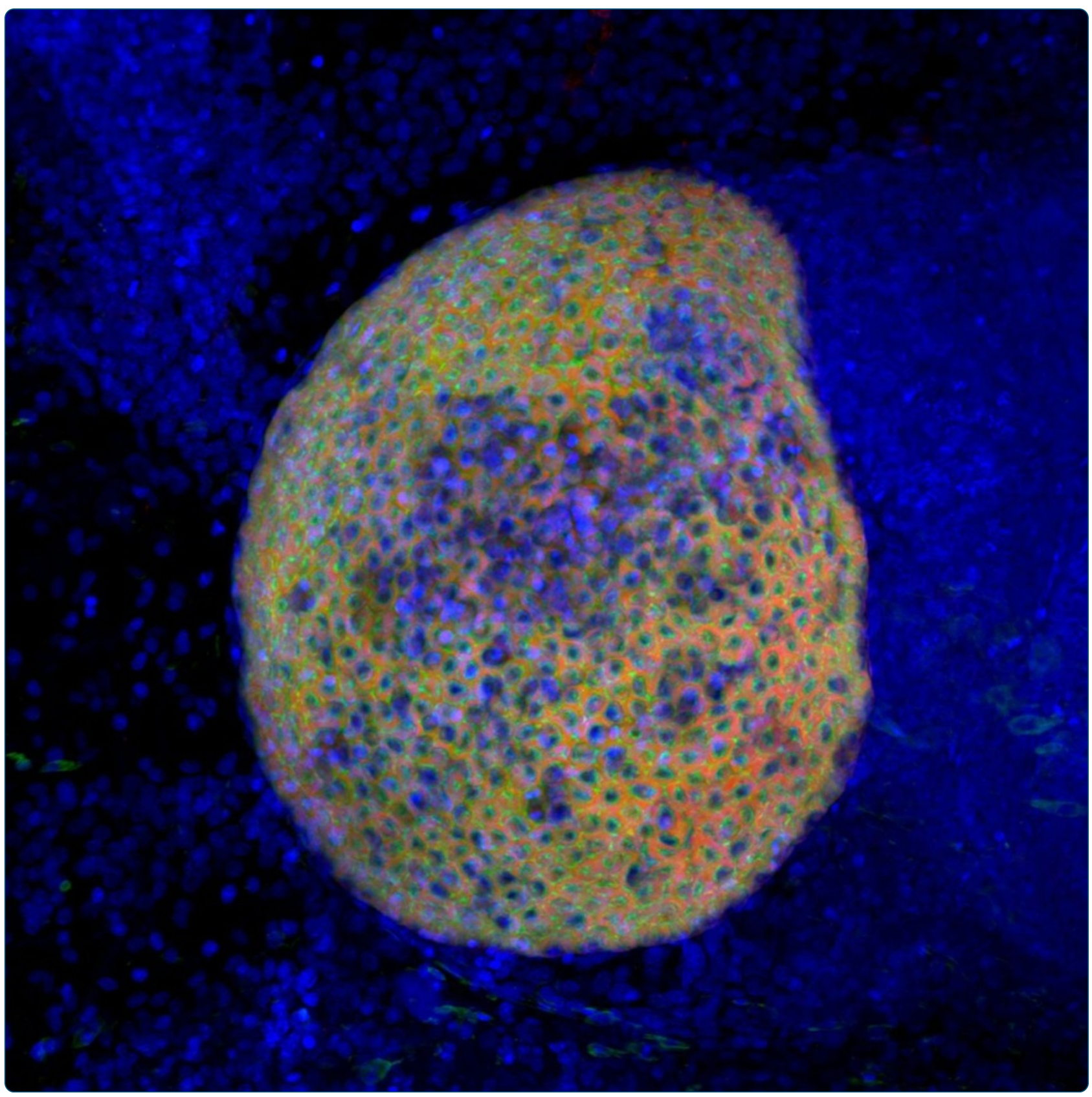

Analysis of the basal chordate Botryllus schlosseri reveals a set of genes associated with fertility

Rodriguez et al.

() Biomed Central 


\title{
Analysis of the basal chordate Botryllus schlosseri reveals a set of genes associated with fertility
}

\author{
Delany Rodriguez ${ }^{1 *}$, Erin N Sanders ${ }^{1}$, Kelsea Farell ${ }^{1}$, Adam D Langenbacher $^{1}$, Daryl A Taketa ${ }^{1}$, \\ Michelle Rae Hopper ${ }^{1}$, Morgan Kennedy ${ }^{1}$, Andrew Gracey ${ }^{2}$ and Anthony W De Tomaso ${ }^{1}$
}

\begin{abstract}
Background: Gonad differentiation is an essential function for all sexually reproducing species, and many aspects of these developmental processes are highly conserved among the metazoa. The colonial ascidian, Botryllus schlosseri is a chordate model organism which offers two unique traits that can be utilized to characterize the genes underlying germline development: a colonial life history and variable fertility. These properties allow individual genotypes to be isolated at different stages of fertility and gene expression can be characterized comprehensively.

Results: Here we characterized the transcriptome of both fertile and infertile colonies throughout blastogenesis (asexual development) using differential expression analysis. We identified genes (as few as 7 and as many as 647) regulating fertility in Botryllus at each stage of blastogenesis. Several of these genes appear to drive gonad maturation, as they are expressed by follicle cells surrounding both testis and oocyte precursors. Spatial and temporal expression of differentially expressed genes was analyzed by in situ hybridization, confirming expression in developing gonads.

Conclusion: We have identified several genes expressed in developing and mature gonads in B. schlosseri. Analysis of genes upregulated in fertile animals suggests a high level of conservation of the mechanisms regulating fertility between basal chordates and vertebrates.
\end{abstract}

Keywords: Ascidian, Tunicate, Fertility, Infertility, Gonad formation, Germline

\section{Background}

Botryllus schlosseri is a colonial ascidian found in shallow subtidal marine habitats around the world. Ascidians are urochordates; the sister group of vertebrates [1-4]. Ascidian embryogenesis results in a chordate tadpole larva (that exhibit chordate characteristics such as a notochord, a dorsal nerve cord, pharyngeal slits, and a post-anal tail) that hatches and undergoes a short free-swimming phase. Larvae disperse, find a suitable substrate, then settle and metamorphose (during this process the tail is reabsorbed and the notochord is lost) into the adult form (called an oozooid; Figure 1) that is now sessile. The oozooid has a complex body plan, including a gastrointestinal tract (incurrent and excurrent siphons, pharynx, stomach, intestine), central and peripheral nervous system, an endocrine system, as well as a complex hematopoietic system and extracorporeal vasculature.

\footnotetext{
* Correspondence: drodriguez@lifesci.ucsb.edu

'Department of Molecular, Cellular, and Developmental Biology, University of California, Santa Barbara, Santa Barbara, CA 93106, USA

Full list of author information is available at the end of the article
}

B. schlosseri belongs to a subset of ascidians that are colonial, and grow not by increasing in size, but by a lifelong, recurring asexual budding process during which entire bodies are regenerated de novo every week, resulting in an expanding colony of genetically identical individuals, called blastozooids (hereafter shortened to zooids). Zooids have the same body plan as the oozooid, and arrange themselves into star-shaped structures called systems (Figure 1A). A single tadpole larva can give rise to a colony consisting of thousands of systems with tens of thousands of zooids. The zooids are connected by a common, extracorporeal vasculature that ramifies throughout the colony. However, while linked by a common vasculature, the zooids and buds are independent, and zooids or systems can be separated from the colony and continue to grow (called subcloning). The ability to collect pieces of the same genotype at different time points is a powerful characteristic of B. schlosseri as an experimental model for these studies [3].

While the entire colony can have a lifespan ranging from nine months to several years, the zooids themselves are transient. After completing a two-week developmental 

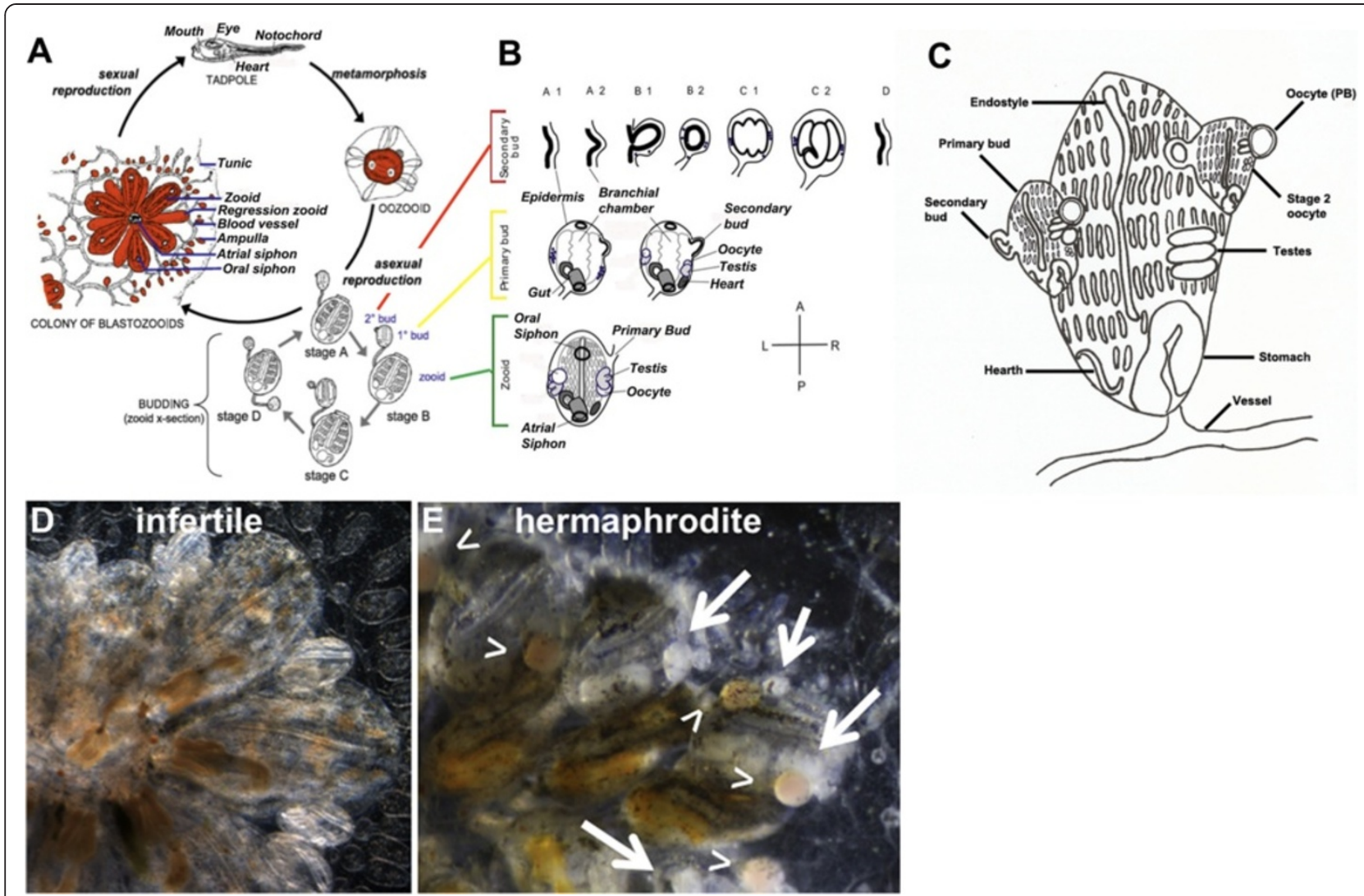

Figure 1 Botryllus schlosseri sexual and asexual development (blastogenesis) and anatomy. A) Sexual cycle showing the larva stage and metamorphosis into oozoid. B) Asexual cycle - blastogenesis: Dorsal views of zooids (green frame), primary buds (yellow frame) and secondary buds (red frame). A secondary bud appears as a thickening of the epidermis and the peribranchial chamber leaflet of the primary bud (stage A1), which evaginates into a closed vesicle (stage B2), followed by organogenesis (stages C1-D). Gonadogenesis occurs in the secondary bud from mobile precursors (blue; stages B1-C2). During takeover (stages C2-D), the secondary bud becomes the primary bud and a new blastogenic cycle begins for the next secondary bud. After the second takeover event, the primary bud opens its siphons and becomes a functional adult (zooid). In fertile colonies (as illustrated here), the hermaphrodite gonad fully matures on both sides of the zooid. C) Schematic showing the anatomy of an adult fertile zooid with two primary buds. $\mathbf{D}$ and $\mathbf{E}$ ) Ventral live image of both infertile and a fertile colonies (respectively). Arrows point to testes and arrowheads point to eggs. Panels A and B are modified from Brown et al. 2009, Laird et al. 2005 and Laird and De Tomaso 2005.

program, zooids have a defined lifespan of one week as an adult. During that week, new zooids are regenerating in a process called blastogenesis. This process is coordinated throughout the colony and arranged spatially such that a colony consists of three co-existing asexual generations within each system (Figure 1A and B) [3-7]. The center of the colony is occupied by the zooids, which are actively feeding and, when fertile, sexually reproducing. They are joined peripherally by primary buds, which are completing development. In turn, these are connected to secondary buds, which are in the initial stages of development. Neither primary nor secondary buds feed or sexually reproduce.

The zooid has a lifespan of one week, then dies in a process called takeover. During takeover, all zooids undergo simultaneous apoptosis and are removed by phagocytic cells in the blood. The primary bud then migrates into the newly vacated region of the colony, opens its siphons and becomes a zooid, the secondary bud becomes the primary bud, and a new secondary bud begins developing from a region of the primary bud called the peribranchial epithelium (Figure 1B,C).

\section{Somatic regeneration}

Blastogenesis is synchronized throughout a colony and takes 14 days under laboratory conditions. This process can be divided into distinct visual stages, each lasting one day and demarcated by major morphogenetic changes (illustrated in Figure 1B). As outlined in Figure 1 (panel B), a new generation starts as a secondary bud, first visible as a thickening of the peribranchial epithelium of a primary bud (Stage A1), which evaginates and forms a closed vesicle (Stage B2). Next, a series of epithelial invaginations and protrusions appear as development proceeds (Stage C1). After 7 days (Stage D), a takeover event occurs, the secondary bud transitions to a primary bud, and over the next 7 days completes organogenesis, including initiating new 
secondary bud(s). At day 14, the zooid of the preceding generation undergoes takeover and is removed, the bud migrates to the new zooid position, and opens its siphons.

\section{Germline development}

Ascidians are hermaphrodites, and adult animals can develop both testes and eggs. Following metamorphosis, colonies undergo an average of eight to twelve developmental cycles prior to the development of gametes (sexual maturity) $[8,9]$. In addition, natural populations show seasonal fertility, and in the lab cycle in and out of reproductive (fertile) and non-reproductive (infertile) states [10-13]. In turn, sexuality is also plastic, and colonies can be either hermaphroditic, or male only (with no oocytes visible) (Figure 1D-E).

When a colony is fertile, development of the gametes is synchronized with somatic development [10-13]. Germline stem cells (GSCs) seed the secondary bud (Figure 1B) and begin to proliferate. However, development of oocytes and testis are not linked. Testes develop in situ, and are visible in the secondary bud at stage B2, and completing development approximately 10 days later, when that secondary bud becomes a zooid [10-13]. In contrast, oocytes appear to take several cycles to mature (described in detail, below), and oocytes at different stages of development (pre-vitellogenic and vitellogenic) will seed the secondary bud along with the GSCs.

\section{Egg development}

B. schlosseri is ovoviviparous and mature eggs are about $300 \mu \mathrm{m}$ in diameter, and are surrounded by a series of cell layers. These include a layer of outer follicle cells (OFC) a layer of inner follicle cells (IFC) and test cells (TC) [14]. Each egg resembles a small ovary consisting of an oocyte, the envelopes (OFC, IFC and TC) and its own oviduct. Oocyte precursors first appear in secondary buds, ripen in primary buds, and ovulate when the primary buds are transitioning to mature zooids during takeover [14-16]. Oocyte development takes place in the primary bud from stages $\mathrm{A} 1$ to $\mathrm{C} 2$ and can be described as 5 stages: At stage 1 , oocyte precursors are $10 \mu \mathrm{m}$ in diameter, with a high nuclear to cytoplasmic ratio. At stage 2 , the oocyte diameter increases up to $50 \mu \mathrm{m}$. At stage 3 oocyte diameter is approximately $80 \mu$. At stage 4 , the oocyte diameter is $120 \mu \mathrm{m}$, and vitellogenesis, the process of secretion of nutrients into the oocyte by follicle cells, is initiated. The diameter of stage 5 oocytes is $220 \mu \mathrm{m}$, vitellogenesis is almost completed, with yolk granules becoming larger. At the end of the blastogenic cycle one to four oocytes mature and are ovulated into the peribranchial space during takeover (stage D). Usually a number (approximately 6 per primary bud) of oocytes remain arrested at stage 2 (in a previtellogenic stage) which can move from the zooid into the blood stream and reach a new primary bud where they can potentially mature in successive blastogenic generations [3].

To better understand the mechanisms of gonad differentiation and fertility, we used mRNA-seq to identify genes that are differentially expressed between fertile and infertile colonies. Using differential expression analysis combined with in situ hybridization, we have identified a number of genes associated with fertility in Botryllus, particularly genes expressed by follicle cells - surrounding both testis and oocyte precursors - that may drive maturation. This study is the first step to comprehensively characterize the mechanisms of gonad maturation and fertility in Botryllus schlosseri.

\section{Results and discussion}

The recent publication of a draft genome sequence for Botryllus schlosseri has identified homologs of vertebrate genes known for their function in lymphoid-mediated immunity as well as eye, ear and heart function [17]. Although this is an important step towards establishing Botryllus as a model organism, an analysis of gene expression dynamics throughout the blastogenic cycle is an important tool to further strengthen this nonconventional model system. One of the limitations of a newly established model organism is that we can infer the function of most proteins in Botryllus only based on comparison to homologs in other species or analysis of conserved protein domains.

To study spatial and temporal gene expression in Botryllus, we combined transcriptomics, quantitative RT-PCR and in situ hybridization. To explore the genes involved in gonad formation and fertility, mRNA seq analysis was performed at each stage of the blastogenic cycle (A1, A2, B1, B2, C1, C2 and D) on a total of 3 fertile genotypes and 3 infertile genotypes (Additional file 1: Figure S1 and Additional file 2: Figure S3 and Additional file 3: Table S1, Additional file 4: Table S2, Additional file 5: Table S3, Additional file 6: Table S4, Additional file 7: Table S5, Additional file 8: Table S6, Additional file 9: Table S7). After Quality Control analysis (see Methods), the sequences were mapped to our publicly available Botryllus schlosseri EST database Bot_asmb assembly (04.05.2011, A. Gracey) (consisting of 50,107 contigs and representing several genotypes, both fertile but nonpregnant and infertile, at different stages of the blastogenic cycle. See Methods for further details.) (Additional file 10: Table S8 and Additional file 11: Table S9). In order to identify putative homologs of the ESTs in our database, we performed a translated BLAST (blastx) analysis using the non-redundant human protein database (NCBI version 4/ 25/13) as well as non-redundant protein databases for Mus musculus, Drosophila melanogaster, Ciona intestinalis and Danio rerio (an E-value of $1.0 \times 10-4$ was chosen as the cutoff for a "homolog" for the purpose of this study; 
Additional file 3: Table S1, Additional file 4: Table S2, Additional file 5: Table S3, Additional file 6: Table S4, Additional file 7: Table S5, Additional file 8: Table S6, Additional file 9: Table S7). Contigs that are differentially expressed (DE) between infertile and fertile animals were detected by DESeq with a false discovery rate (FDR) of 10\% (Additional file 3: Table S1, Additional file 4: Table S2, Additional file 5: Table S3, Additional file 6: Table S4, Additional file 7: Table S5, Additional file 8: Table S6, Additional file 9: Table S7, Additional file 12: Table S10 and Additional file 13: Table S11) [18]. Table 1 shows the number of DE contigs at each stage of the blastogenic cycle at a 10\% FDR (Additional file 3: Table S1, Additional file 4: Table S2, Additional file 5: Table S3, Additional file 6: Table S4, Additional file 7: Table S5, Additional file 8: Table S6, Additional file 9: Table S7, Additional file 12: Table S10 and Additional file 13: Table S11).

Many of the homologs of these contigs have been previously demonstrated to play a role in germline development, fertility and/or fertilization in humans and other organisms (Table 2). In Botryllus, conserved genes required for embryonic germ cell specification, such as vasa, piwi and nanos, are expressed in primitive germ cells that are present in juveniles as well as in both fertile and infertile adult animals [19-23]. Therefore, genes that are upregulated in fertile animals in our analysis are likely to be involved in gonad formation/ maturation and germ cell differentiation.

The number of differentially expressed genes varied greatly between stages of the blastogenic cycle, from a minimum of 7 at stage $C 1$ to a maximum of 647 at stage B1 (Table 1).

In Botryllus spermatogenesis begins at stage A1 in the testis of the zooid and continues until stage B2 when mature sperm is released through the oral siphon out into the water [3]. Consistent with this timing, we found that based on homology, a significant portion of the genes upregulated in stages A1 and A2 are functionally related to sperm formation (Additional file 3:

$\begin{aligned} & \text { Table } \mathbf{1} \text { Number of differentially expressed EST's (10\% } \\
& \text { FDR) at each stage of the blastogenic cycle and number } \\
& \text { of those EST's with human homologs }\end{aligned}$
\begin{tabular}{lrc}
\hline $\begin{array}{l}\text { Stage of } \\
\text { blastogenesis }\end{array}$ & $\begin{array}{l}\text { Number of differetially } \\
\text { expressed genes (10\%FDR) }\end{array}$ & $\begin{array}{l}\text { Number of } \\
\text { human homologs }\end{array}$ \\
\hline A1 & 592 & 290 \\
A2 & 136 & 70 \\
B1 & 647 & 304 \\
B2 & 125 & 59 \\
C1 & 7 & 2 \\
C2 & 61 & 32 \\
D & 221 & 122 \\
\hline
\end{tabular}

Table S1, Additional file 4: Table S2, Additional file 14: Table S12, Additional file 15: Table S13, Additional file 16: Table S14, Additional file 17: Table S15, Additional file 18: Table S16, Additional file 19: Table S17, Additional file 20: Table S18, Additional file 21: Table S19). Since most of these homologs are involved in spermatogenesis in vertebrates (references in Table 2), these data suggest some degree of conservation of the mechanisms governing spermatogenesis between ascidians and vertebrates.

To investigate the spatial and temporal expression pattern of DE genes, we performed quantitative RT-PCR (qPCR) and fluorescent in situ hybridization (FISH) for genes that were selected from the most highly DE genes with human homologs: p-selectin (slep), otoancorin (otoa), tetraspanin-8 (tspan8), low-density lipoprotein receptor (ldlr), testis-specific serine/threonine kinase 1 (tsk1) and 2 (tsk2) and genes with known roles in fertility in other organisms: estradiol $17 \beta$ dehydrogenase-8 (hsd1738), zona pellucida sperm binding protein 1 (zp1), vitellogenin-1 (vtg1), tolloid-like-1 (tll1). All of these genes were analyzed in fertile colonies at each stage of the blastogenic cycle by qPCR (Additional file 22: Figure S2).

We found expression of these genes in: testes or developing testes (otoancorin, tetraspanin-8, testis-specific serine/threonine kinase 1, vitellogenin); localized to maturing eggs (vitellogenin, ldlr, zona-pellucida sperm binding protein-1, tolloid-like protein-1); oocytes at stage 2 (estradiol $17 \beta$ dehydrogenase-8, p-selectin, testis-specific serine/threonine kinase 2, tetraspanin-8); and other tissues (zona-pellucida sperm binding protein 1, p-selectin, and ldlr) (Figure 2).

Testis-specific serine/threonine protein kinases phosphorylate myelin basic protein and histones in vitro [24]. The testicular germ cell-specific expression of the mouse homologs suggests that these genes play an important role at and after the meiotic phase of spermatogenesis [25]. In Botryllus, Testis-specific serine/threonine protein kinases, tsk-1, tsk-2 and tsk-6 are upregulated in fertile animals based on our DE analysis (tsk-1: 203-fold upregulated at stage A1; tsk-2: 462-fold upregulated at stage B1; tsk-6: 57-fold upregulated at stage A1). qPCR analysis showed that both $t s k-1$ and $t s k-2$ are highly upregulated between stages A2 and B2, and in situ hybridization indicates that the mRNA is expressed on developing testes (Figure 2) consistent with a crucial role of these genes in spermatogenesis.

In mammals, Otoancorin is specific to sensory epithelia of the inner ear but in humans it has also been classified as a testis-selective cancer/testis gene [26]. Based on our DE analysis, the Botryllus homolog of otoancorin is upregulated 54-fold in fertile animals at stage A1. By in situ hybridization, otoancorin shows strong expression from stage A1 through B1 in the testes of the primary bud (pb) 
Table 2 Differentially expressed genes upregulated in fertile versus infertile colonies and their human and/or ascidian homologs

\begin{tabular}{|c|c|c|c|c|c|c|c|c|c|}
\hline $\begin{array}{l}\mathrm{DE} \text { at Stage }(\mathrm{s}) \text { of } \\
\text { Blastogenesis }\end{array}$ & EST 5-11 contig name & $\begin{array}{l}\text { Homo sapiens or } \\
\text { Ascidian homologue }\end{array}$ & $\begin{array}{l}\text { BaseMean } \\
\text { Infertile }\end{array}$ & $\begin{array}{l}\text { BaseMean } \\
\text { Fertile }\end{array}$ & FoldChange & pval & padj & Function or Expression & Reference \\
\hline$A 1 *, A 2, B 1, C 2$ and $D$ & CAP3_round1_contig_7511 & Histone $\mathrm{H} 1.0$ & 5.33 & 5031.92 & 944.26 & 1.15E-09 & 3.39E-07 & $\begin{array}{l}\text { Regulates gene transcription through } \\
\text { chromatin remodeling, facilitating } \\
\text { expression of fertility-related genes. }\end{array}$ & [49] \\
\hline$A 1, B 1 *, B 2, C 1, C 2$ and D & CAP3_round1_contig_5534 & Vitellogenin-1 & 49.17 & 45603.55 & 927.44 & $2.26 \mathrm{E}-15$ & $4.49 \mathrm{E}-12$ & $\begin{array}{l}\text { Involved in secretion of nutrients } \\
\text { into the oocyte by follicle cells }\end{array}$ & [14-16] \\
\hline$A 1 *, B 1$, and $B 2$ & Bot_c25439 & $\begin{array}{l}\text { F-box only protein } \\
24 \text { isoform } 3\end{array}$ & 1.18 & 1062.39 & 901.21 & $1.58 \mathrm{E}-19$ & $1.23 \mathrm{E}-15$ & $\begin{array}{l}\text { Substrate-recognition component } \\
\text { of the SCF (SKP1-CUL1-F-box } \\
\text { protein)-type E3 ubiquitin } \\
\text { ligase complex }\end{array}$ & [50] \\
\hline $\mathrm{A} 1$ and $\mathbf{B} 1 *$ & Bot_rep_c36004 & $\begin{array}{l}\text { Erythrocyte band } 7 \text { integral } \\
\text { membrane protein isoform a }\end{array}$ & 2.78 & 1395.43 & 502.30 & 4.21E-19 & $1.64 \mathrm{E}-15$ & Expressed on red blood cells. & [51] \\
\hline $\mathrm{A} 1$ and $\mathbf{B} 1 *$ & Bot_rep_c36244 & $\begin{array}{l}\text { Testis-specific serine/ } \\
\text { threonine-protein kinase } 2\end{array}$ & 0.72 & 333.98 & 462.92 & $1.59 \mathrm{E}-15$ & $3.11 \mathrm{E}-12$ & $\begin{array}{l}\text { Expressed in both mouse } \\
\text { and human sperm. }\end{array}$ & [52] \\
\hline$C 2 *$ & Bot_c1378 & $\begin{array}{l}\text { Microfibrillar-associated } \\
\text { protein } 4\end{array}$ & 4.24 & 1334.72 & 314.97 & $1.84 \mathrm{E}-06$ & 3.61E-03 & $\begin{array}{l}\text { Involved in photoprotection } \\
\text { of the skin. }\end{array}$ & [53] \\
\hline $\mathbf{A} 1 *, B 1$ and $B 2$ & Bot_c2674 & Kelch-like protein 10 & 3.42 & 766.95 & 223.81 & 5.53E-04 & $1.41 \mathrm{E}-01$ & $\begin{array}{l}\text { Encodes a component of } \\
\text { intercellular bridges in } \\
\text { Drosophila egg chambers. }\end{array}$ & [54] \\
\hline$A 1, A 2, B 1 *$, and $B 2$ & CAP3_round1_contig_5576 & Histone $\mathrm{H} 2 \mathrm{~B}$ type $1-\mathrm{L}$ & 3.98 & 1152.34 & 289.37 & 7.74E-15 & $1.10 \mathrm{E}-11$ & $\begin{array}{l}\text { Required to condense chromatin } \\
\text { in sperm, removes heterochromatin } \\
\text { marks, facilitating gene expression }\end{array}$ & [55] \\
\hline$A 1, A 2, B 1 *$ and $B 2$ & Bot_rep_c35370 & $\begin{array}{l}\text { Creatine kinase S-type } \\
\text { mitochondrial }\end{array}$ & 7.80 & 2193.66 & 281.17 & $4.12 \mathrm{E}-18$ & $1.38 \mathrm{E}-14$ & $\begin{array}{l}\text { Is expressed in cardiac } \\
\text { and striated muscle. }\end{array}$ & {$[56]$} \\
\hline $\mathbf{A} 1 *, B 1$ and $D$ & Bot_c3513 & Tolloid-likeprotein 1 & 0.61 & 159.21 & 261.65 & $2.42 \mathrm{E}-08$ & $5.34 \mathrm{E}-06$ & $\begin{array}{l}\text { Mammalian tolloid (BMP-1) is a } \\
\text { proteinase involved in ovarian } \\
\text { tissue remodeling }\end{array}$ & [35] \\
\hline$A 1 * A 2, B 1$ and $B 2$ & Bot_rep_c45338 & $\begin{array}{l}\text { Testis-specific serine/ } \\
\text { threonine-protein kinase } 1\end{array}$ & 6.67 & 1358.25 & 203.49 & $4.31 \mathrm{E}-16$ & $1.34 \mathrm{E}-12$ & $\begin{array}{l}\text { Testicular germ cell-specific } \\
\text { expression, possible role at } \\
\text { and after the meiotic } \\
\text { phase of spermatogenesis }\end{array}$ & {$[26,57]$} \\
\hline$A 1, B 1, B 2 *, C 2$ and $D$ & Bot_rep_c45532 & $\begin{array}{l}\text { Low density lipoprotein- } \\
\text { related protein } 1\end{array}$ & 5.68 & 1129.89 & 199.07 & $3.26 \mathrm{E}-10$ & $2.18 \mathrm{E}-06$ & $\begin{array}{l}\text { Mediates endocytosis of } \\
\text { cholesterol-rich LDL. In mice, } \\
\text { LDLR is expressed in germ cells }\end{array}$ & {$[58]$} \\
\hline B1, B2 and C2* & Bot_c16824 & $\begin{array}{l}\text { Zona Pellucida sperm } \\
\text { binding protein-1 }\end{array}$ & 2.88 & 568.93 & 197.42 & $2.72 \mathrm{E}-06$ & 4.70E-03 & $\begin{array}{l}\text { Involved in oocyte development, } \\
\text { protection, sperm binding. }\end{array}$ & {$[33,59]$} \\
\hline$A 1, A 2, B 1 *$ and $D$ & Bot_c13044 & P-Selectin & 1.89 & 362.01 & 191.12 & 9.33E-11 & $4.21 \mathrm{E}-08$ & $\begin{array}{l}\text { Expressed in the oolema of } \\
\text { oocytes in hamsters and } \\
\text { humans, as well as in sperm } \\
\text { following the acrosomal reaction }\end{array}$ & [37-39] \\
\hline $\mathrm{A} 1$ and $\mathbf{B} 1$ * & CAP3 round1 contig 8583 & $\begin{array}{l}\text { Ubiquitin-conjugating } \\
\text { enzyme E2 R2 }\end{array}$ & 10.47 & 1902.72 & 181.78 & $1.04 \mathrm{E}-11$ & $6.27 \mathrm{E}-09$ & $\begin{array}{l}\text { Ubiquitin-protein ligase complex, } \\
\text { mediates ubiquitination and } \\
\text { proteosomal degradation of target } \\
\text { proteins during spermatogenesis }\end{array}$ & [60] \\
\hline
\end{tabular}




\begin{tabular}{|c|c|c|c|c|c|c|c|c|}
\hline $\mathrm{A} 1$ and $\mathbf{B} \mathbf{1}^{*}$ & Bot_c2928 & $\begin{array}{l}\text { NAD+-specific isocitrate } \\
\text { dehydrogenase beta precursor }\end{array}$ & 7.87 & 1072.58 & 136.14 & $1.78 \mathrm{E}-05$ & $2.23 E-03$ & $\begin{array}{l}\text { Possible role in oxidation of } \\
\text { isocitrate to alpha-ketoglutarate } \\
\text { in the citric acid cycle. }\end{array}$ \\
\hline $\mathbf{A} \mathbf{1}^{*}$ and $\mathrm{B} 1$ & Bot_rep_c45410 & $\begin{array}{l}\text { Outer dense fiber of } \\
\text { sperm tails } 3 \text {-like } 2\end{array}$ & 5.51 & 750.03 & 135.99 & $3.47 \mathrm{E}-14$ & $3.69 \mathrm{E}-11$ & $\begin{array}{l}\text { Structural protein surrounding the } \\
\text { axoneme in both the middle piece } \\
\text { and principal piece of the sperm tail. }\end{array}$ \\
\hline $\mathbf{A} \mathbf{1}^{*}$ and $\mathrm{B} 1$ & Bot_c16543 & CD81 antigen (Tetraspanin-8) & 1.19 & 150.88 & 125.95 & $2.73 \mathrm{E}-10$ & 9.77E-08 & $\begin{array}{l}\text { Expressed by granulosa cells } \\
\text { surrounding the oocyte in mice. } \\
\text { Reduced fertility in CD81-/- null } \\
\text { mice, possible role in } \\
\text { acrosomal reaction }\end{array}$ \\
\hline$A 1 *, B 1, B 2$ & CAP3_round1_contig_7986 & Meltrin-S & 5.49 & 625.35 & 113.78 & $1.78 \mathrm{E}-13$ & $1.74 \mathrm{E}-10$ & $\begin{array}{l}\text { Mediates cleavage of proteoglycans } \\
\text { during the release of the oocyte } \\
\text { in mammals }\end{array}$ \\
\hline$A 1, B 1 *$ & CAP3_round1_contig_6892 & $\begin{array}{l}\text { ADAM metallopeptidase } \\
\text { domain } 12\end{array}$ & 35.70 & 3526.16 & 98.75 & 1.55E-09 & $5.14 \mathrm{E}-07$ & $\begin{array}{l}\text { ADAMs play roles in spermatogenesis } \\
\text { and sperm function, potentially by } \\
\text { effecting maturation of sperm and } \\
\text { their adhesion and migration }\end{array}$ \\
\hline $\mathrm{A} 1, \mathbf{A} \mathbf{2}^{*}$, and $\mathrm{B} 1$ & CAP3_round1_contig_4222 & Cyclin A1 & 8.29 & 808.46 & 97.45 & 4.87E-05 & 3.39E-02 & Involved in cell cycle. \\
\hline $\mathrm{A} 1$ and $\mathbf{B} \mathbf{1}^{*}$ & Bot_rep_c35625 & Serine racemase & 14.60 & 1226.71 & 84.00 & $1.37 \mathrm{E}-13$ & $1.37 E-10$ & $\begin{array}{l}\text { Expressed in human testes,pecifically } \\
\text { in spermatogonia, spermatocytes, } \\
\text { spermatids, Leydig and Sertoli cells }\end{array}$ \\
\hline $\mathrm{A} 1, \mathrm{~B} 1 *$, B2 & CAP3_round1_contig_4558 & $\begin{array}{l}\text { Fibrous sheath-interacting } \\
\text { protein } 2\end{array}$ & 29.98 & 2389.31 & 79.67 & $3.66 \mathrm{E}-11$ & $1.90 \mathrm{E}-08$ & $\begin{array}{l}\text { Expressed in late spermatocyte } \\
\text { development. }\end{array}$ \\
\hline $\mathbf{A} 1 *, B 1$ and $D$ & Bot_c1197 & Hemicentin-1 precursor & 22.88 & 1722.58 & 75.28 & $4.39 \mathrm{E}-13$ & $3.55 E-10$ & $\begin{array}{l}\text { Facilitates the gliding of the } \\
\text { developing gonad along epithelial } \\
\text { basement membranes and } \\
\text { germline cellularization. }\end{array}$ \\
\hline$A 1 *, A 2$ and $B 1$ & CAP3_round1_contig_9899 & $\begin{array}{l}\text { Testis-specific serine/threonine- } \\
\text { protein kinase } 6\end{array}$ & 21.59 & 1245.79 & 57.70 & $5.29 \mathrm{E}-12$ & $3.18 \mathrm{E}-09$ & $\begin{array}{l}\text { Essential for spem production } \\
\text { and function }\end{array}$ \\
\hline $\mathbf{A} \mathbf{1}^{*}, \mathrm{~B} 1$ and $\mathrm{D}$ & CAP3_round1_contig_9042 & OTOA protein & 91.00 & 4925.43 & 54.12 & $2.39 \mathrm{E}-12$ & $1.54 \mathrm{E}-09$ & $\begin{array}{l}\text { Expressed in sensory epithelia of } \\
\text { the inner ear.t Has also been } \\
\text { classified as } \\
\text { a testis-selective cancer/testis } \\
\text { (CT) gene }\end{array}$ \\
\hline$A 1, A 2, B 1 *, C 2$ and $D$ & Bot_rep_c50436 & Fukutin & 21.63 & 1124.36 & 51.99 & $6.28 \mathrm{E}-06$ & $8.64 \mathrm{E}-04$ & $\begin{array}{l}\text { Mouse homozygous-null embryos } \\
\text { showed folding of the egg cylinder, } \\
\text { leakage of maternal red blood cells } \\
\text { into the yolk sac cavity. }\end{array}$ \\
\hline$A 1 *, A 2$ and $D$ & Bot_c2465 & $\begin{array}{l}\text { ATP-binding cassette } \\
\text { sub-family B member } \\
5 \text { isoform } 1\end{array}$ & 59.69 & 2393.08 & 40.10 & $5.75 \mathrm{E}-11$ & $2.56 \mathrm{E}-08$ & $\begin{array}{l}\text { In Drosophila, ABC transporters } \\
\text { efflux prenylated peptides out } \\
\text { of somatic gonadal precursors to } \\
\text { serve as chemoattractants } \\
\text { for migrating germ cells }\end{array}$ \\
\hline
\end{tabular}


Table 2 Differentially expressed genes upregulated in fertile versus infertile colonies and their human and/or ascidian homologs (Continued)

\begin{tabular}{|c|c|c|c|c|c|c|c|c|c|}
\hline$A 2^{*}$ & Bot_c25254 & Retinol dehydrogenase 12 & 37.74 & 1127.87 & 29.88 & 2.41E-08 & 1.87E-04 & $\begin{array}{l}\text { In Botryllus schlosseri retinoic } \\
\text { acid signaling is involved } \\
\text { in gonad formation }\end{array}$ & [23] \\
\hline$A 1, B 1 *$ and $D$ & CAP3_round1_contig_9460 & Tubulin beta- $4 \mathrm{~B}$ chain & 351.41 & 10282.63 & 29.26 & $1.61 \mathrm{E}-07$ & $3.41 \mathrm{E}-05$ & $\begin{array}{l}\text { Tubulin is the major constituent } \\
\text { of microtubules; post-translational } \\
\text { modification bu monoglycalation } \\
\text { specifi incorporation into axonemes. }\end{array}$ & [73] \\
\hline A1 and $\mathbf{B} 1^{*}$ & CAP3_round1_contig_2349 & Ciliary dynein heavy chain 9 & 122.18 & 3015.52 & 24.68 & $1.06 \mathrm{E}-08$ & $3.02 \mathrm{E}-06$ & $\begin{array}{l}\text { Possible role in sperm } \\
\text { development or motility }\end{array}$ & {$[74]$} \\
\hline$A 1^{*}, A 2, B 1$ and $D$ & Bot_rep_c36144 & $\begin{array}{l}\text { Cyclic nucleotide-gated } \\
\text { olfactory channel }\end{array}$ & 46.02 & 1050.24 & 22.82 & 7.82E-09 & $1.91 \mathrm{E}-06$ & $\begin{array}{l}\text { Expressed in the flagellum } \\
\text { of mature sperm, involved } \\
\text { in sperm movement }\end{array}$ & [75] \\
\hline$A 1^{*}$ & CAP3_round1_contig_7272 & Cyclin B3 & 280.56 & 1503.78 & 5.36 & 5.99E-04 & $5.22 \mathrm{E}-02$ & Involved in cell cycle regulation & [66] \\
\hline
\end{tabular}

normalized counts from Fertile. FoldChange $=$ fold change from Infertile to Fertile, pval $=p$ value for statistical significance; padj $=p$ value adjusted for multiple testing at $10 \%$ false discovery rate; Differentially expressed (DE) genes at stage(s) of the blastogenic cycle bold and $\left(^{*}\right)$ show the reported basemean infertile and fertile pval, padj for that particular contig at that particular stage. 


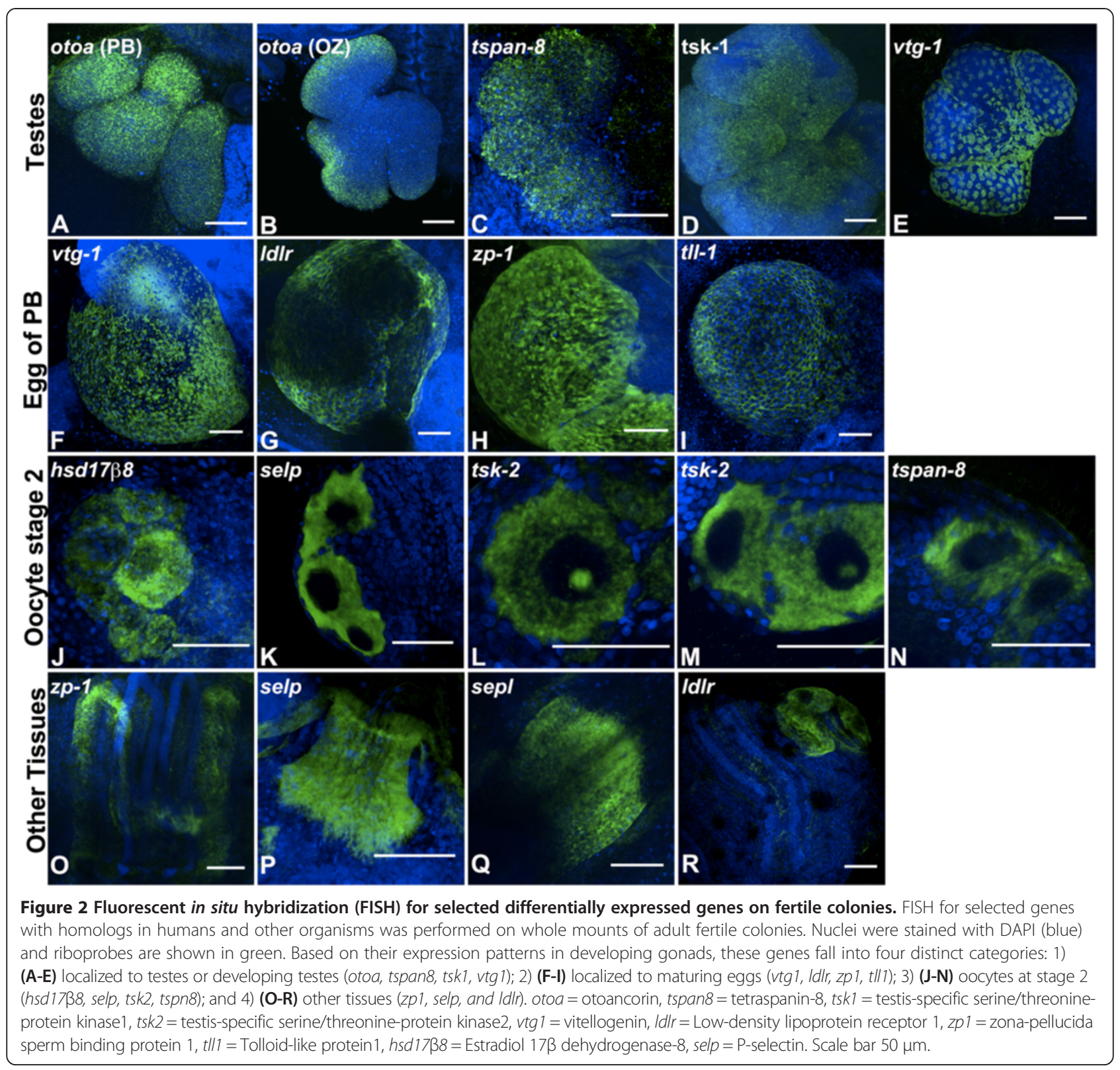

(Figure 2A), indicating that in Botryllus, otoancorin might be involved in spermatogenesis. By qPCR, its expression level is highest in A1, and decreases as the blastogenic cycle continues. Interestingly, testes of the zooid also show signal for otoancorin mRNA, but expression is restricted to the peripheral cells of the testes (Figure 2B).

Tetraspanin/CD9-like is an oocyte factor required for sperm-oocyte fusion [27]. Consistent with these findings in mammals, in situ hybridization shows expression of the Botryllus homolog of tetraspanin-8 on stage 2 oocytes. The ADAM-integrin-tetraspanin complex, known to constitute a network of membrane microdomains called the tetraspanin web, is potentially involved in the migration of prespermatogonia from the center to the periphery of the testicular cords and in the reinitiation of mitotic activity during the initial wave of spermatogenesis [28]. By qPCR, expression of tetraspanin-8 in Botryllus is highest at stage A1, coinciding with the initiation of spermatogenesis. Furthermore, our DE analysis revealed a 125-fold upregulation of tetraspanin-8 in fertile animals at stage A1. In situ hybridization showed cells expressing tetraspanin- 8 mRNA in the testes of the primary bud, and suggests that the role of Tetraspanin proteins in spermatogenesis is likely to be conserved between Botryllus and vertebrates.

Vitellogenins are lipophosphoglycoproteins that are produced under female hormonal control in large central organs (fat body in insects; liver in higher animals) 
and are transported in the circulation to the female gonads [29]. In Botryllus, a vitellogenin homolog is 927fold upregulated in fertile animals at stage B1. Two novel isoforms of vitellogenin, both of which possess vWF-D and CT domains but not a lipovitellin or phosvitin domain, are expressed in the gonad of the ascidian Halocynthia roretzi [30]. In situ hybridization revealed that mRNAs of these proteins are specifically expressed in oocytes and test cells, accessory cells in the perivitelline space of ascidian eggs. Immunohistochemistry showed that these proteins are localized around the surface of test cells in immature oocytes [30]. In Botryllus, vitellogenin expression is highest at stage B2 (Additional file 22: Figure S2), and, consistent with the findings in Halocynthia, in situ hybridization shows expression on maturing eggs of the primary bud (Figure 2).

Interestingly, vitellogenin mRNA is also expressed by follicle cells on the testes of both the primary bud and the zooid (Figure 2). These cells are restricted to the periphery of the testes and seem to surround them, in contrast to the mRNA's of otoancorin, testis-specific serine/threonineprotein kinase 1 and tetraspanin-8 (Figure 2), which are expressed by cells in the inner compartment of the testes.

To date, all molecularly characterized vitellogenin receptors belong to the low-density lipoprotein receptor (ldlr) supergene family. Ldlr receptors localized in coated pits on the surface of growth-competent oocytes are able to accumulate in the yolk high concentrations of vitellogenin and other ligands they recognize [29]. A Botryllus schlosseri homolog of $l d l r$ is upregulated 199-fold in fertile animals at stage B2, and qPCR analysis shows that expression of $l d l r$ in Botryllus is highest at stage A2 (Additional file 22: Figure S2). By in situ hybridization, we found that $l d l r$ is expressed in follicle cells of maturing eggs in the primary bud (Figure 2), suggesting that it might function as a vitellogenin-receptor during oocyte maturation.

In Halocynthia roretzi, a $120-\mathrm{kDa}$ transmembrane protein with a zona pellucida domain and a 13 EGF-like repeats (HrVC120), has been shown to be the receptor in the vitelline coat that binds to sperm [31]. Ciona intestinalis has several genes related to $\mathrm{HrVC120}$ that are exclusively expressed in developing oocytes but not in eggs [32]. We found a gene containing a Zona Pellucida domain, $z p-1$, that is highly upregulated in fertile animals (197-fold change at stage $\mathrm{C} 2$ ) and highly expressed at stage A1 (Additional file 22: Figure S2). By in situ hybridization, we found that $z p-1$ is expressed by the follicle cells that surround the egg in the primary bud. To our knowledge this is the first report of a gene with a Zona Pellucida domain in a colonial ascidian. This finding reflects the close relationship of these animals with vertebrates and the fact that this domain has been maintained in deuterostomes suggests that it is indispensable for sperm-egg interaction $[27,33]$.
Mammalian Tolloid (Bmp-1) is a proteinase involved in ovulation. During ovarian tissue remodeling, it contributes to the maturation of procollagen molecules and the deposition of collagen fibrils [34]. In Botryllus, a tolloid-like protein 1 homolog is expressed on follicle cells of maturing oocytes of the primary bud and is upregulated 261-fold in fertile animals at stage A1 (Figure 2).

A Botryllus schlosseri homolog of estradiol $17 \beta$ dehydrogenase- 8 (hsd17ß8) is highly upregulated in fertile animals (5.4-fold at stage B1), and as expected, given its involvement in estrogen metabolism [35], its mRNA localizes to oocytes at stage 2 (Figure 2).

A Botryllus schlosseri homolog of p-selectin (selp) is upregulated 191-fold in fertile animals at stage B1. By in situ hybridization, this gene is expressed on several stages of oocytes (Figure 2). The function of this protein in germ cells is poorly understood, but it is expressed in the oolema of oocytes in hamsters and humans, as well as in sperm following the acrosomal reaction, and is hypothesized to be involved in sperm-oocyte adhesion [36-38]. We measured the diameter of the oocytes expressing $p$-selectin, and found that their size increased as the blastogenic cycle advanced (Table 3 ). Cells positive for $p$-selectin mRNA range from $16-21 \mu \mathrm{m}$ in diameter at stage A1, suggesting they are stage 2 oocytes as classified by Manni [3,14-16]. Stage 2 oocytes are defined as being greater than $10 \mu \mathrm{m}$ in diameter (bigger than stage 1 oocyte precursors) but less than $50 \mu \mathrm{m}$ in diameter (smaller than stage 3 oocytes). By the middle of the blastogenic cycle, p-selectin-positive cells can reach up to $39 \mu \mathrm{m}$ (stage B2). By the end of blastogenesis, one or two p-selectin-positive cells per primary bud will be about $42 \mu \mathrm{m}$ in diameter, and could indicate that these cells are committed to become mature oocytes [14-16]. This supports the concept that there is a persisting reservoir of egg-precursors, and only one or two of those cells will increase in size to move on to stage 3 and develop into the egg of the primary bud for the following blastogenic cycle [14-16].

\begin{tabular}{|c|c|c|c|}
\hline Stage & Range of diameters $(\mu \mathrm{m})$ & Mean $(\mu \mathrm{m})$ & $\mathrm{SD}(\mu \mathrm{m})$ \\
\hline A1 & $16-21$ & 26.35 & 4.14 \\
\hline$A 2$ & $20-30$ & 20.42 & 2.98 \\
\hline B1 & $25-37$ & 35.58 & 5.46 \\
\hline B2 & 23-39 & 29.76 & 8.44 \\
\hline $\mathrm{C} 1$ & $22-35$ & 31.35 & 5.59 \\
\hline$C 2$ & $19-42$ & 28.48 & 5.82 \\
\hline D & $15-22$ & 18.18 & 7.33 \\
\hline
\end{tabular}


Unexpectedly, we found that stage 2 oocytes were positive for the mRNA of testis-specific serine/threonine-protein kinase 2 gene at stage B1 and B2 of the blastogenic cycle. Moreover, a strong nucleolus like signal was observed in about $30-40 \%$ of positive cells. This finding could indicate a previously unknown function of this gene in oogenesis.

Finally, we observed that some of the genes upregulated in fertile animals are expressed in tissues outside of the germ line. Particularly $p$-selectin mRNA is expressed on the oral and excurrent siphons of both the zooid and primary bud (Figure 3B arrows). Interestingly, at stage D of the blastogenic cycle, $p$-selectin positive cells are arranged in a calyx shape (Figure 2Q) of the primary bud as it transitions to a zooid during takeover. A Botryllus schlosseri homolog of Zona pellucida binding protein-1 showed mRNA expression on cells that run along the endostyle of both zooid and primary bud, while $l d l r$ showed positive mRNA expression on secondary bud tissue at stage B1.

The set of fertility-related genes we have identified represents the first reported molecular markers for a variety of Botryllus schlosseri anatomical structures. Specifically, we found transcripts expressed by the testes (both developing and mature testes), by follicle cells surrounding both maturing oocytes and testes, by oocytes at stage 2 and by the siphons (oral and excurrent). These markers will undoubtedly serve as a valuable resource for other researchers examining fertility in Botryllus.

To obtain a broader perspective and explore the biological roles of the genes identified in our DE analysis, we performed a gene ontology (GO) analysis on the human homologs of differentially expressed genes (Table 1) at each stage of the blastogenic cycle (Human genes were used as a proxy in our GO analysis because Botryllus ESTs lack GO annotation) [39-41]. Specifically, annotation based on biological processes provided significant insight into functional changes related to fertility throughout the blastogenic cycle, and are discussed here. Other GO annotations (All annotations and molecular function) are included in Additional file 14: Table S12, Additional file 15: Table S13, Additional file 16: Table S14, Additional file 17: Table S15, Additional file 18: Table S16, Additional file 19: Table S17, Additional file 20: Table S18, Additional file 21: Table S19, Additional file 23: Table S20, Additional file 24: Table S21, Additional file 25: Table S22, Additional file 26: Table S23, Additional file 27: Table S24, Additional file 28: Table S25, Additional file 29: Table S26, Additional file 30: Table S27, Additional file 31: Table S28, Additional file 32: Table S29, Additional file 33: Table S30, Additional file 34: Table S31, Additional file 35: Table S32, Additional file 36: Table S33, Additional file 37: Table S34, Additional file 38: Table S35, Additional file 39: Table S36, Additional file 40: Table S37 and Additional file 41: Table S38. Furthermore, we conducted Inter Pro analysis to find conserved protein domains (Additional file 17: Table S15, Additional file 21: Table S19, Additional file 26: Table S23, Additional file 30: Table S27, Additional file 37: Table S34, and Additional file 41: Table S38).

At stages A1 and A2, 592 (290 with human homologs) and 136 (70 with human homologs) genes are upregulated in fertile animals, respectively. GO analysis revealed that

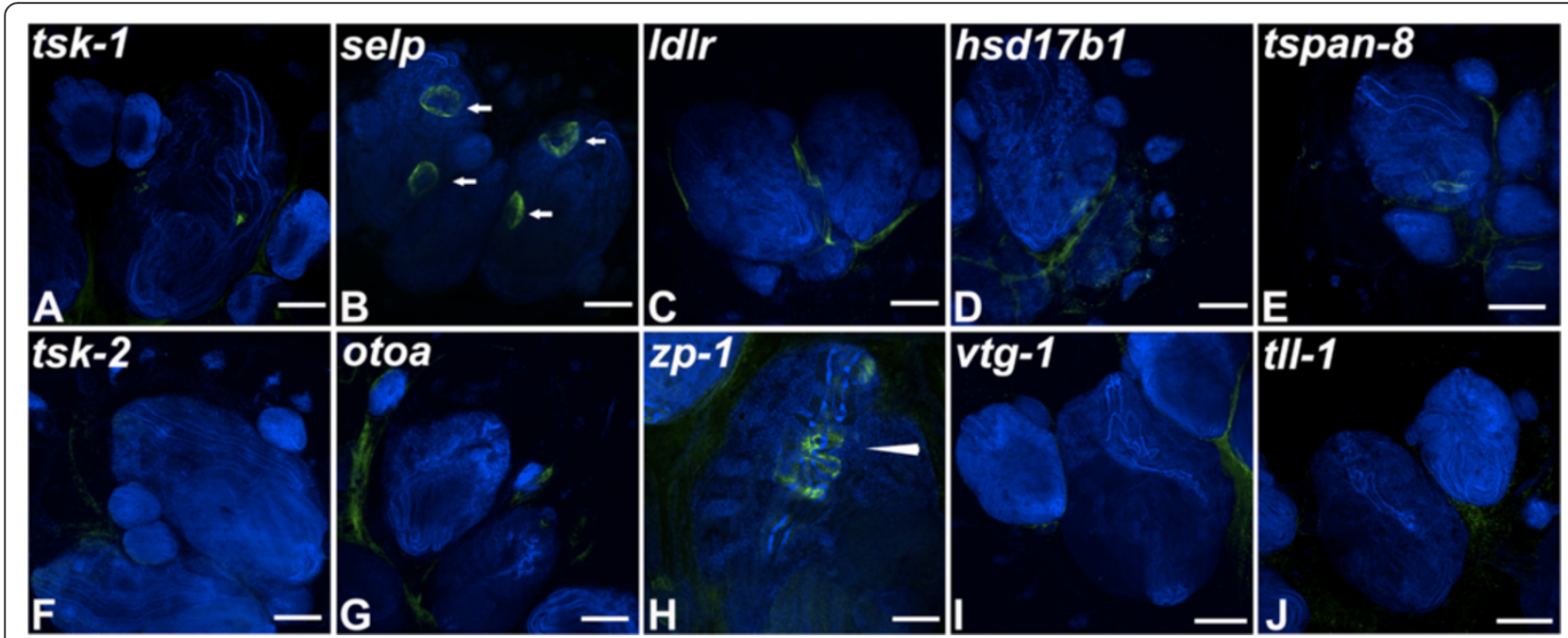

Figure 3 Fluorescent in situ hybridization (FISH) for selected differentially expressed genes on infertile colonies. FISH for selected genes was performed on whole mounts of adult infertile colonies (A-J). Nuclei were stained with DAPI (blue) and riboprobes are shown in green. Expression of genes detected in fertile colonies is absent in juveniles except for p-selectin (localizing to both oral and excurrent siphons) as indicated by arrows (B) and Zona-pellucida sperm binding protein1 (localizing to the endostyle) as indicated by the arrowhead $\mathbf{( H )}$. otoa = otoancorin, tspan $8=$ tetraspanin-8, tsk1 = testis-specific serine/threonine-protein kinase1, tsk2 = testis-specific serine/threonine-protein kinase2, vtg $1=$ vitellogenin $|d| r=$ Low-density lipoprotein receptor $1, z p 1=$ zona-pellucida sperm binding protein 1 , tll1= Tolloid-like protein 1, hsd $17 b 8=$ Estradiol $17 \beta$ dehydrogenase8, selp = P-selectin. Scale bar $200 \mu \mathrm{m}$ 
genes related to male meiosis, spermatogenesis, cilium, proteolysis, microtubule based movement, meiosis, spermatid development, cilliary or flagellar motility, female gamete generation and male meiosis are upregulated (Additional file 14: Table S12, Additional file 15: Table S13, Additional file 16: Table S14, Additional file 18: Table S16, Additional file 19: Table S17 and Additional file 24: Table S18), correlating with the fact that spermatogenesis begins in this timeframe. Inter Pro analysis revealed that these genes contain domains such as EGF, LDLR, BMP, Selectin and Meiotic recombination Spo11, among others (Additional file 21: Table S19 and Additional file 26: Table S23). These results are congruent with previous nonmolecular observations indicating that gametogenesis starts during these stages.

At stages B1 and B2, 647 and 125 genes are DE with 304 and 59 human homologs respectively. Genes related to male meiosis, spermatogenesis, spermatid development, microtubule-based movement, cell differentiation, motility, filipodium assembly, flagellar motility, cell adhesion, female gamete generation and apoliprotein binding are upregulated in fertile animals (Additional file 23: Table S20, Additional file 24: Table S21, Additional file 25: Table S22, Additional file 27, Table S24, Additional file 28: Table S25 and Additional file 29: Table S26). Inter Pro analysis revealed that these genes contain domains such as EGF, Kringle, CUB, Speract/Scavenger Kelch, Calcium binding, ADAM, and Peptidase S1/S6/ M12A, BMP1/Tolloid, Zona pellucida sperm-binding protein and LDLR among others (Additional file 26: Table S23 and Additional file 30: Table S27). These results reflect the complex biological processes occurring during these stages, which also have the highest number of DE genes, and are consistent with the timing of sperm maturation and release.

At stage $\mathrm{C} 1$ and $\mathrm{C} 2,7$ and 61 genes are DE with 2 and 32 human homologs respectively. The predominant GO terms at these stages included oocyte maturation, oocyte growth, lipoprotein metabolic process, regulation of cholesterol transport, positive regulation of estrogen receptor, extracellular matrix disassembly, and tissue remodeling, among others (Additional file 31: Table S28, Additional file 32: Table S29, Additional file 34: Table S31, Additional file 35: Table S32 and Additional file 36: Table S33). The Inter Pro analysis for this stage revealed domains such as: Apple-like, LDLR, Kringe, Aquaporin, Tetraspanin, EGF, Zona Pellucida sperm-binding protein, Peptidase S1/S6/M12A and FY rich, among others (Additional file 33: Table S30 and Additional file 37: Table S34). At these stages maturing oocytes rapidly increase in size and are preparing to move into the branchial basket of the zooid.

Finally at stage D 221 genes are DE (with 122 human homologs). GO analysis revealed the presence of annotations including cell adhesion, carbohydrate metabolism, regulation of developmental process and response to corticosteroids stimulus, proteolysis, lipoprotein transport, cholesterol transport, estrogen receptor signaling pathway, oocyte growth (Additional file 38: Table S35, Additional file 39: Table S36 and Additional file 40: Table S37) and the Inter Pro analysis of the genes upregulated at this stage revealed the following protein domains: EGF, Notch, CUB, LDLR, Selectin, and Peptidases S1/S1A/S6, among others (Additional file 41: Table S38). At this stage mature oocytes begin to transition from the peribranchial cavity into the branchial basket of the new zooid.

In summary, our GO analysis has revealed a number of genes with potential involvement in spermatogenesis at stages A1-B2, correlating with what has been described for Botryllus schlosseri [3]. The Botryllus homologs of these genes are promising candidates for future studies on testes maturation and sperm production. Homologs of genes with reported roles in lipid and steroid metabolism are upregulated at stages B1-D, representing key processes involved in oocyte maturation in other species that may be conserved in Botryllus [42-44].

\section{Conclusions}

This manuscript represents the first step in the comprehensive characterization of gonad differentiation and fertility in Botryllus schlosseri. We have analyzed the transcriptomes of both infertile and fertile colonies and characterized the spatial and temporal expression of highly expressed genes involved in fertility. Our findings suggest a high level of conservation of the mechanisms regulating fertility between basal chordates and vertebrates. Some of the genes characterized in this study were found to have unexpected spatial localization, such as testis serine/threonine kinase 2, which is expressed by egg precursors. Another example is vitellogenin, which localizes to both follicle cells surrounding the egg and equivalent cells surrounding the testes.

Interestingly, known germline markers such as vasa, nanos and piwi were not significantly differentially expressed between fertile and infertile colonies, most likely because both juveniles and infertile colonies have immature germ cells expressing these genes. We have identified specific markers for both developing gonads (and mature testes) throughout the blastogenic cycle in zooids, primary buds and secondary buds. Some of these markers are now being used to investigate the phenomenon of induced juvenile fertility in Botryllus schlosseri (Di Maio et al. unpublished).

In future studies, we will investigate differential gene expression between male and hermaphroditic colonies, which will allow us to characterize genes used exclusively in male or female gamete development and identify genes governing the process by which Botryllus schlosseri assumes a given reproductive state. 


\section{Methods}

\section{Animals}

All mariculture procedures have been described previously (Boyd et al., 1986). Briefly, we collected pregnant Botryllus schlosseri colonies from the Santa Barbara Marina, California. Individual colonies were tied to $3 \times 5$-cm glass slides and placed $5 \mathrm{~cm}$ opposite another glass slide (called the settlement slide) in a slide rack. The slide rack was placed into an aquarium, and within a few days the tadpoles hatched, swam to the settlement slide, and metamorphosed into the adult body plan (oozooid). Over 95\% of the tadpoles hatch and immediately swim to and settle on the juxtaposed slide [45]. Animals are reared in $5 \mathrm{~L}$ tanks supplemented with food in suspension daily, and food is not limiting [45]. Only isolated genotypes reared in our mariculture facility were used for this study.

To explore only the genes involved in gonad formation and fertility, mRNA seq analysis was performed at every stage of the blastogenic cycle (A1, A2, B1, B2, C1, C2 and $\mathrm{D}$, each stage as described by bud morphogenesis based on in vivo and histological features [46]) on a total of 3 fertile samples (SB801, SB841 and Mix genotypes SB802a, SB804, SB722 ) and 3 infertile samples (SB802d, SB-BB-001 and Mix genotypes SB831, SB645, SB714, SB841, SB842 ).

\section{RT-PCR, cloning, and quantitative PCR}

Total RNA was isolated from whole colonies using Nucleo-Spin II columns from Macherey Nagel, and mRNA was isolated using the NEB Magnetic Bead Isolation kit. cDNA was made using Superscript II from Invitrogen. For RT-PCR, we used Clontech Advantage following the manufacturers' recommendations for PCR conditions.

PCR products were isolated using Qiagen columns, then cloned into the Promega Easy-T vector and transformed using competent NEB5 $\alpha$ from NEB. Single colonies were picked and inserts amplified using colony PCR and Clontech Advantage. PCR products were prepared for sequencing then sent for Sanger sequencing at the UC Berkeley Sequencing Facility.

Quantitative PCR (QPCR) analysis was done as described previously [47]. Briefly, Q-PCR was carried out using a LightCycler 480 II (Roche) and LightCycler DNA Master SYBR Green I detection (Roche, 12015099001). The thermocycling profile was as follows: 5 minutes at $95^{\circ} \mathrm{C}, 45$ cycles of $95^{\circ} \mathrm{C}$ for $10 \mathrm{sec}, 50-60^{\circ} \mathrm{C}$ for $10 \mathrm{sec}$, and $72^{\circ} \mathrm{C}$ for $10 \mathrm{sec}$. All gene expression data was normalized to elongation factor $1-\alpha(E F 1-\alpha)$ as a reference house keeping gene and reported as relative expression using the $2^{-\Delta \Delta C t}$ method.

Three biological and technical replicates were used for each gene.

Primers for QPCR are shown in Table 4.
Table 4 Primers sequence for QPCR

\begin{tabular}{|c|c|}
\hline Gene name & Primers sequence $5^{\prime}-3^{\prime}$ \\
\hline \multirow[t]{2}{*}{ tll-1 } & Fwd-TTGCTGCACATCGAGTGTCT \\
\hline & Rev-GTGCTACAAGTTGCGAGTGC \\
\hline \multirow[t]{2}{*}{ tsk-2 } & Fwd-GGCGTGGATTACCTTCACGA \\
\hline & Rev-AAGCTCCATACGTCGGCAAT \\
\hline \multirow[t]{2}{*}{ Idlr } & Fwd-GTGGTTCTGGAACCGGATGT \\
\hline & Rev-TGACGAGTGCTCATCGGAAC \\
\hline \multirow[t]{2}{*}{ tspan-8 } & Fwd-AGTGGGAATTTGGGCTCTCG \\
\hline & Rev-AGTCACAAGCGTCATCGGAG \\
\hline \multirow[t]{2}{*}{ tsk-1 } & Fwd-TTCGAAACACTCTGGGCGAA \\
\hline & Rev-TCGGATGACTCAAGAGGGGT \\
\hline \multirow[t]{2}{*}{$v \operatorname{tg}-1$} & Fwd-CGAGTCATGTATGTCCGCGA \\
\hline & Rev-TGAAAGGCGAGCTGCAGTAA \\
\hline \multirow[t]{2}{*}{$z p-1$} & Fwd-GCAACGATCCATTTCCGTCG \\
\hline & Rev-CTCGTCCAATGTGGCAGAGT \\
\hline \multirow[t]{2}{*}{ otoa } & Fwd-AGATTTCGAGTTGCTITIACAGGTTAC \\
\hline & Rev-CAATACTTCAAAGACTGTTTCCTCTGT \\
\hline \multirow[t]{2}{*}{ hsd17ß8 } & Fwd-GCGGTCTGGTAAGCTTTGGT \\
\hline & Rev-GTCGGACGCAAGGAACAAAC \\
\hline \multirow[t]{2}{*}{ selp } & Fwd-CTATTCTCTATACCCCGAAGGCTITAC \\
\hline & Rev-CTTCAGAGATTGTGAAAGAAGCAAT \\
\hline
\end{tabular}

\section{mRNA seq}

Total RNA was isolated from whole colonies using the Nucleo-Spin RNA II kit (MN). Libraries were prepared and sequenced at the USC Epigenome Center using kits from Illumina following the manufacturers' instructions. Paired-end libraries were generated for each sample and sequenced with an Illumina Hi-Seq 2000. The data supporting the results of this article have been deposited in NCBI's Gene Expression Omnibus [48,49] and are accessible through GEO Series accession number GSE62112 (http://www.ncbi.nlm.nih.gov/geo/query/acc. cgi?acc $=$ GSE62112). After RNASeq each paired end (PE) library was first checked for quality control (QC) using the software FastQC (http://www.bioinformatics.babraham.ac.uk/projects/fastqc/ ) with an average score of 28 across all bases (Illumina 1.5 encoding). Using FASTQ Trimmer we removed the adapters of the sequences by removing the first 12 bases of each read. All reads pairs passing QC were mapped using BOWTIE (2012 version 0.12.7) [50] to the public EST database Bot_asmb assembly (04.05.2011, A. Gracey) (http://octopus.obs-vlfr.fr/ public/botryllus/blast_botryllus.php). Bot_asmb assembly (04.05.2011, A. Gracey), consisting of 50,107 contigs, is an assembly of two cDNA libraries generated from a mixture of Botryllus schlosseri genotypes at each stage of 
the blastogenic cycle and representing both infertile and fertile states. The libraries used to construct Bot_asmb assembly (04.05.2011, A. Gracey) consist of: (1) 10,000 arrayed clones sequenced from 5 ' to 3' ends using the Sanger method (200,000 sequences total with an average length of 950 base pairs) and (2) 454 sequencing of the same RNA with an average length of 400 base pairs. The number of reads mapping to each EST were obtained with Sam2Counts (Samtools version 0.1.18) and differential expression analysis was performed with DESeq 1.10.1 using triplicates for the analysis and a false discovery rate of $10 \%$ [18]. Fragments per kilobase per million (FPKM) were calculated using RSEM 1.2.3 for each paired-end library for each genotype at each stage of the blastogenic cycle for both infertile and fertile colonies. To identify putative homologs we blasted (BLASTX) to the non-redundant protein databases of Homo sapiens Mus musculus, Drosophila melanogaster, Ciona intestinalis and Danio reirio with an E-value cutoff of $1 \times 10^{-4}$.

All bioinformatics analysis was performed on a Desktop computer running Ubuntu 12.10 and equipped with $16 \mathrm{~GB}$ of RAM.

\section{Gene Ontology and InterPro analysis}

The list of human homologs of differentially expressed Botryllus contigs was submitted to GeneCodis 3, an online modular enrichment tool [39-41]. For this analysis, the following annotations were selected: GO Biological Process, GO Molecular Function and InterPro Motifs. The statistical parameters for these analyses were as follows: First, for co-occurrence analyses of annotations, a minimum support of 3 genes was required. Second, the statistical method to compute p-values was the hypergeometric test. Finally, to correct p-values for multiple hypothesis testing, FDR estimation was utilized. Of particular interest to this study were processes and pathways with a known role in fertility and gametogenesis.

\section{Fluorescent in situ hybridization (FISH)}

Fragments of Botryllus schlosseri Estradiol 17- $\beta$-dehydrogenase 8 (hsd17b8), P-Selectin (selp), Otoancorin (otoa), Testis-specific serine/threonine-protein kinase 2 (tsk2), Vitellogenin (vtg1), Tetraspanin 8 (tspan8), Zona-pellucida sperm binding protein 1 (zp1), Low-Density Lipoprotein receptor (ldlr), Testis-specific serine/threonine-protein kinase 1 (tsk1), Tolliod-like 1 (tll1), ranging in size from $200 \mathrm{bp}-1 \mathrm{~kb}$ were amplified with Advantage cDNA polymerase (Clontech) and cloned into the pGEM-T Easy vector (Promega). SP6 or T7 RNA polymerase (Roche) were used to generate antisense RNA probes labeled with digoxigenin (Roche) or DNP (Perkin Elmer).

Single systems of fertile or infertile Botryllus were fixed with $4 \%$ formaldehyde in $0.1 \mathrm{M}$ MOPS $\mathrm{pH} 7.5$, $0.5 \mathrm{M} \mathrm{NaCl}$ for 3 hours and then transferred to methanol. To eliminate pigmentation, animals were bleached in $6 \% \mathrm{H}_{2} \mathrm{O}_{2}$ /methanol and then stored in methanol at $-20^{\circ} \mathrm{C}$. After rehydration, animals were permeabilized with proteinase $\mathrm{K}(10 \mu \mathrm{g} / \mathrm{ml}$ for $30 \mathrm{~min})$ and then post-fixed with $4 \%$ formaldehyde. Prehybridization was carried out for 4 hours at $65^{\circ} \mathrm{C}$ in hybridization buffer (65\% formamide, 5X SSC, 1X Denhardt's solution, $0.1 \%$ Tween-20, $5 \mathrm{mg} / \mathrm{ml}$ torula yeast RNA, $50 \mu \mathrm{g} / \mathrm{ml}$ heparin), followed by hybridization with DIG- and DNPlabeled probes in hybridization buffer overnight at $65^{\circ} \mathrm{C}$. After washing off unbound probes, DIG-labeled probe was detected with an anti-DIG HRP-conjugated antibody (Roche) and TSA Plus fluorescent tyramide conjugate (Perkin Elmer). For double labeling, the HRP-conjugated anti-DIG antibody was then inactivated with $2 \% \mathrm{H}_{2} \mathrm{O}_{2}$ in PBS with $0.1 \%$ Triton X-100 and DNP-labeled probes were detected with anti-DNP HRP-conjugated antibody (Perkin Elmer) and TSA Plus fluorescent tyramide conjugate (Perkin Elmer). After washing in PBS, specimens were flat-mounted with Vectashield (Vector Labs) and imaged on an Olympus Fluoview 1000 Spectral confocal microscope equipped with a 40X oil immersion objective. All FISH experiments were performed in triplicates. Only consistent reproducible staining throughout the whole-mount colonies was reported.

Primers for in situ hybridization probes are shown in Table 5.

Table 5 Primer sequences for in situ hybridization probes

\begin{tabular}{|c|c|}
\hline Gene symbol & Primers sequence used for each gene $5^{\prime}-3^{\prime}$ \\
\hline \multirow[t]{2}{*}{ hsd17 $\beta 8$} & Fwd-GCGGTCTGGTAAGCTTTGGT \\
\hline & Rev-GTCGGACGCAAGGAACAAAC \\
\hline \multirow[t]{2}{*}{ selp } & Fwd-CCTTCAGTTGCAACAAGGGC \\
\hline & Rev-ACCGTTTCGGAGAGTTTCCC \\
\hline \multirow[t]{2}{*}{ tsk-2 } & Fwd-AAAATGCGAGAACATCCTACTCA \\
\hline & Rev-TTCTGTTAGGTCCCCTGATTGTA \\
\hline \multirow[t]{2}{*}{ otoa } & Fwd-CGCAGCGCAGGATTAAACTC \\
\hline & Rev-GCCGTATTTGTCGTGGATGC \\
\hline \multirow[t]{2}{*}{$v \operatorname{tg}-1$} & Fwd-CCGAACCGTACGGATACCTG \\
\hline & Rev-TACGTTTTGGACGAAGGCGA \\
\hline \multirow[t]{2}{*}{ tspan-8 } & Fwd-CAATTTGGCGCTGTTCCTCG \\
\hline & Rev-CACGACTCTTACGCGTATCCA \\
\hline \multirow[t]{2}{*}{$z p-1$} & Fwd-AGACGTGGTACCCATAGCCT \\
\hline & Rev-ACGCTTATCGTGCAAGTGGA \\
\hline \multirow[t]{2}{*}{ Idlr } & Fwd-GAATTTGCAGCTCGCTCTCG \\
\hline & Rev-CATGACGAGTGCTCATCGGA \\
\hline \multirow[t]{2}{*}{ tsk-1 } & Fwd-GGAAAATGCTCGGAACGGTG \\
\hline & Rev-CCCGAAAAACGGATGTCCA \\
\hline \multirow[t]{2}{*}{ tIl-1 } & Fwd-TTGCTGCACATCGAGTGTCT \\
\hline & Rev-TGCCGAAGAAAACGCTGTTG \\
\hline
\end{tabular}




\section{Measurement of stage 2 oocytes}

After FISH (above) the diameter of selp positive cells were measured using FIJI image processing software. Each primary bud (average of five buds per experiment) with positive cells (average of ten positive oocytes stage 2) were measured of total of three colonies at each stage of the blastogenic cycle. Standard deviation was calculated using Microsoft Office Excel 2011.

\section{Additional files}

Additional file 1: Figure S1. Scatter plots of Differentially Expressed genes throughout the entire blastogenic cycle of Botryllus schlosseri. Plot of normalized mean versus log2 fold change infertile versus fertile for each stage of the blastogenic cycle. Red circles indicate genes that are significant at a $10 \%$ false discovery rate (FDR)

Additional file 2: Figure S3. Heat Maps of Differentially expressed genes of both infertile and fertile colonies at each stage of the blastogenic cycle of Botryllus schlosseri. Aqua color indicates relative low abundance/ expression and darker blue indicates higher abundance/expression.

Additional file 3: Table S1. Differentially Expressed genes between infertile and fertile colonies of Botryllus schlosseri at stage A1: baseMean = mean normalized counts average over all samples from both conditions, baseMean Infertile = mean normalized counts from Infertile samples, baseMean Fertile $=$ mean normalized counts from Fertile samples, foldChange $=$ fold change from Infertile to Fertile, log2FoldChange $=$ the logarithm (to basis 2) of fold change, pval $=p$ value for the statistical significance, $\operatorname{padj}=\mathrm{p}$ value adjusted for multiple testing with the Benjamini-Hochberg procedure.

Additional file 4: Table S2. Differentially Expressed genes between infertile and fertile colonies at stage of Botryllus schlosseri A2: baseMean = mean normalized counts average over all samples from both conditions, baseMean Infertile = mean normalized counts from Infertile samples, baseMean Fertile $=$ mean normalized counts from Fertile samples, foldChange $=$ fold change from Infertile to Fertile, log2FoldChange $=$ the logarithm (to basis 2 ) of fold change, pval $=p$ value for the statistical significance, $\operatorname{pad} j=\mathrm{p}$ value adjusted for multiple testing with the Benjamini-Hochberg procedure.

Additional file 5: Table S3. Differentially Expressed genes between infertile and fertile colonies of Botryllus schlosseri at stage B1: baseMean = mean normalized counts average over all samples from both conditions, baseMean Infertile = mean normalized counts from Infertile samples, baseMean Fertile $=$ mean normalized counts from Fertile samples, foldChange $=$ fold change from Infertile to Fertile, log2FoldChange $=$ the logarithm (to basis 2) of fold change, pval $=p$ value for the statistical significance, $\operatorname{padj}=\mathrm{p}$ value adjusted for multiple testing with the Benjamini-Hochberg procedure.

Additional file 6: Table S4. Differentially Expressed genes between infertile and fertile colonies of Botryllus schlosseri at stage B2: baseMean = mean normalized counts average over all samples from both conditions, baseMean Infertile = mean normalized counts from Infertile samples, baseMean Fertile $=$ mean normalized counts from Fertile samples, foldChange $=$ fold change from Infertile to Fertile, log2FoldChange $=$ the logarithm (to basis 2) of fold change, pval $=p$ value for the statistical significance, padj $=p$ value adjusted for multiple testing with the Benjamini-Hochberg procedure.

Additional file 7: Table S5. Differentially Expressed genes between infertile and fertile colonies of Botryllus schlosseri at stage C1: baseMean = mean normalized counts average over all samples from both conditions, baseMean Infertile = mean normalized counts from Infertile samples, baseMean Fertile $=$ mean normalized counts from Fertile samples, foldChange $=$ fold change from Infertile to Fertile, log2FoldChange $=$ the logarithm (to basis 2 ) of fold change, pval $=p$ value for the statistical significance, $\operatorname{padj}=\mathrm{p}$ value adjusted for multiple testing with the Benjamini-Hochberg procedure.
Additional file 8: Table S6. Differentially Expressed genes between infertile and fertile colonies of Botryllus schlosseri at stage C2: baseMean = mean normalized counts average over all samples from both conditions, baseMean Infertile = mean normalized counts from Infertile samples, baseMean Fertile $=$ mean normalized counts from Fertile samples, foldChange $=$ fold change from Infertile to Fertile, log2FoldChange = the logarithm (to basis 2) of fold change, pval $=p$ value for the statistical significance, $\operatorname{padj}=p$ value adjusted for multiple testing with the Benjamini-Hochberg procedure.

Additional file 9: Table S7. Differentially Expressed genes between infertile and fertile colonies of Botryllus schlosseri at stage D: baseMean = mean normalized counts average over all samples from both conditions, baseMean Infertile = mean normalized counts from Infertile samples, baseMean Fertile $=$ mean normalized counts from Fertile samples, foldChange $=$ fold change from Infertile to Fertile, log2FoldChange $=$ the logarithm (to basis 2 ) of fold change, pval = p value for the statistical significance, $\operatorname{padj}=\mathrm{p}$ value adjusted for multiple testing with the Benjamini-Hochberg procedure.

Additional file 10: Table S8. Mapped reads to EST 5-11 for Fertile Samples.

Additional file 11: Table S9. Mapped reads to EST 5-11 for Infertile Samples.

Additional file 12: Table S10. FPKM for each stage of the blastogenic cycle for Fertile Samples.

Additional file 13: Table S11. FPKM for each stage of the blastogenic cycle for Infertile Samples.

Additional file 14: Table S12. Gene Ontology analysis (All annotations) of human homologs of differentially expressed genes at stage A1. Items $=$ Codes of annotations, Items Details = description of annotations, Support = number of genes in input list with a given annotation, List size $=$ number of genes in input list, Reference Support $=$ number of genes in reference list with a given annotation, Reference size $=$ number of genes in reference list, Hyp = Hypergeometric p-value, Hyp c = corrected Hypergeometric $\mathrm{p}$-value (FDR), Genes = genes with given annotation in the input list.

Additional file 15: Table S13. Gene Ontology analysis of Biological Processes of human homologs of differentially expressed genes at stage A1. Items = Codes of annotations, Items Details = description of annotations, Support = number of genes in input list with a given annotation, List size $=$ number of genes in input list, Reference Support $=$ number of genes in reference list with a given annotation, Reference size $=$ number of genes in reference list, $\mathrm{Hyp}=$ Hypergeometric p-value, Hyp c = corrected Hypergeometric p-value (FDR), Genes = genes with given annotation in the input list.

Additional file 16: Table S14. Gene Ontology analysis of Molecular Function of human homologs of differentially expressed genes at stage A1. Items $=$ Codes of annotations, Items Details = description of annotations, Support = number of genes in input list with a given annotation, List size $=$ number of genes in input list, Reference Support $=$ number of genes in reference list with a given annotation, Reference size $=$ number of genes in reference list, Hyp = Hypergeometric p-value, Hyp c = corrected Hypergeometric $p$-value (FDR), Genes = genes with given annotation in the input list.

Additional file 17: Table S15. Inter Pro analysis of human homologs of differentially expressed genes at stage A1. Items = Codes of annotations, Items Details = description of annotations, Support = number of genes in input list with a given annotation, List size $=$ number of genes in input list, Reference Support $=$ number of genes in reference list with a given annotation, Reference size $=$ number of genes in reference list, $\mathrm{Hyp}=$ Hypergeometric p-value, Hyp c = corrected Hypergeometric p-value (FDR), Genes = genes with given annotation in the input list.

Additional file 18: Table S16. Gene Ontology analysis (All annotations) of human homologs of differentially expressed genes at stage A2. Items = Codes of annotations, Items Details = description of annotations, Support $=$ number of genes in input list with a given annotation, List size $=$ number of genes in input list, Reference Support $=$ number of genes in reference list with a given annotation, Reference size $=$ number of 
genes in reference list, Hyp = Hypergeometric $p$-value, Hyp c = corrected Hypergeometric $p$-value (FDR), Genes = genes with given annotation in the input list.

Additional file 19: Table S17. Gene Ontology analysis of Biological Processes of human homologs of differentially expressed genes at stage A2. Items $=$ Codes of annotations, Items Details = description of annotations, Support = number of genes in input list with a given annotation, List size $=$ number of genes in input list, Reference Support $=$ number of genes in reference list with a given annotation, Reference size $=$ number of genes in reference list, $\mathrm{Hyp}=$ Hypergeometric $p$-value, Hyp c = corrected Hypergeometric $p$-value (FDR), Genes = genes with given annotation in the input list.

Additional file 20: Table S18. Gene Ontology analysis of Molecular Function of human homologs of differentially expressed genes at stage A2. Items = Codes of annotations, Items Details = description of annotations, Support = number of genes in input list with a given annotation, List size $=$ number of genes in input list, Reference Support $=$ number of genes in reference list with a given annotation, Reference size $=$ number of genes in reference list, Hyp $=$ Hypergeometric $p$-value, Hyp c $=$ corrected Hypergeometric $p$-value (FDR), Genes = genes with given annotation in the input list.

Additional file 21: Table S19. Inter Pro analysis of human homologs of differentially expressed genes at stage A2. Items =Codes of annotations, Items Details = description of annotations, Support $=$ number of genes in input list with a given annotation, List size = number of genes in input list, Reference Support = number of genes in reference list with a given annotation, Reference size $=$ number of genes in reference list, Hyp $=$ Hypergeometric $p$-value, Hyp $c=$ corrected Hypergeometric $p$-value (FDR), Genes = genes with given annotation in the input list.

Additional file 22: Figure S2. Quantitative PCR of selected differentially expressed genes for fertile colonies throughout the entire blastogenic cycle of Botryllus schlosseri. Plots show upregulation of the selected genes for each gene are normalized to stage A1 showing fold change at each stage of the blastogenic cycle. Control reference gene is ef-1a. Error bars are from three biological and three technical replicates.

Additional file 23: Table S20. Gene Ontology analysis (All annotations) of human homologs of differentially expressed genes at stage B1. Items $=$ Codes of annotations, Items Details = description of annotations, Support $=$ number of genes in input list with a given annotation, List size $=$ number of genes in input list, Reference Support $=$ number of genes in reference list with a given annotation, Reference size $=$ number of genes in reference list, Hyp = Hypergeometric $p$-value, Hyp c = corrected Hypergeometric $p$-value (FDR), Genes = genes with given annotation in the input list

Additional file 24: Table S21. Gene Ontology analysis of Biological Processes of human homologs of differentially expressed genes at stage B1. Items $=$ Codes of annotations, Items Details $=$ description of annotations, Support = number of genes in input list with a given annotation, List size $=$ number of genes in input list, Reference Support $=$ number of genes in reference list with a given annotation, Reference size $=$ number of genes in reference list, Hyp $=$ Hypergeometric $p$-value, $\operatorname{Hyp} c=$ corrected Hypergeometric $p$-value (FDR), Genes = genes with given annotation in the input list.

Additional file 25: Table S22. Gene Ontology analysis of Molecular Function of human homologs of differentially expressed genes at stage B1. Items = Codes of annotations, Items Details = description of annotations, Support $=$ number of genes in input list with a given annotation, List size $=$ number of genes in input list, Reference Support $=$ number of genes in reference list with a given annotation, Reference size $=$ number of genes in reference list, $\mathrm{Hyp}=$ Hypergeometric $p$-value, Hyp c = corrected Hypergeometric $p$-value (FDR), Genes = genes with given annotation in the input list.

Additional file 26: Table S23. Inter Pro analysis of human homologs of differentially expressed genes at stage B1. Items = Codes of annotations, Items Details = description of annotations, Support = number of genes in input list with a given annotation, List size $=$ number of genes in input list, Reference Support $=$ number of genes in reference list with a given annotation, Reference size $=$ number of genes in reference list, Hyp = Hypergeometric $p$-value, Hyp c = corrected Hypergeometric $p$-value (FDR), Genes = genes with given annotation in the input list.

Additional file 27: Table S24. Gene Ontology analysis (All annotations) of human homologs of differentially expressed genes at stage B2. Items $=$ Codes of annotations, Items Details $=$ description of annotations, Support $=$ number of genes in input list with a given annotation, List size $=$ number of genes in input list, Reference Support $=$ number of genes in reference list with a given annotation, Reference size $=$ number of genes in reference list, Hyp $=$ Hypergeometric $p$-value, Hyp c = corrected Hypergeometric $p$-value (FDR), Genes = genes with given annotation in the input list.

Additional file 28: Table S25. Gene Ontology analysis of Biological Processes of human homologs of differentially expressed genes at stage B2. Items = Codes of annotations, Items Details = description of annotations, Support = number of genes in input list with a given annotation, List size $=$ number of genes in input list, Reference Support $=$ number of genes in reference list with a given annotation, Reference size $=$ number of genes in reference list, Hyp = Hypergeometric $p$-value, Hyp c = corrected Hypergeometric $p$-value (FDR), Genes = genes with given annotation in the input list.

Additional file 29: Table S26. Gene Ontology analysis of Molecular Function of human homologs of differentially expressed genes at stage B2. Items $=$ Codes of annotations, Items Details $=$ description of annotations, Support = number of genes in input list with a given annotation, List size $=$ number of genes in input list, Reference Support $=$ number of genes in reference list with a given annotation, Reference size $=$ number of genes in reference list, Hyp $=$ Hypergeometric $p$-value, Hyp c = corrected Hypergeometric $p$-value (FDR), Genes = genes with given annotation in the input list.

Additional file 30: Table S27. Inter Pro analysis of human homologs of differentially expressed genes at stage B2. Items = Codes of annotations, Items Details = description of annotations, Support = number of genes in input list with a given annotation, List size $=$ number of genes in input list, Reference Support = number of genes in reference list with a given annotation, Reference size $=$ number of genes in reference list, Hyp = Hypergeometric $\mathrm{p}$-value, Hyp c = corrected Hypergeometric $p$-value (FDR), Genes = genes with given annotation in the input list.

Additional file 31: Table S28. Gene Ontology analysis of Biological Processes of human homologs of differentially expressed genes at stage C1. Items = Codes of annotations, Items Details = description of annotations, Support = number of genes in input list with a given annotation, List size $=$ number of genes in input list, Reference Support $=$ number of genes in reference list with a given annotation, Reference size $=$ number of genes in reference list, Hyp = Hypergeometric $p$-value, Hyp c = corrected Hypergeometric $p$-value (FDR), Genes = genes with given annotation in the input list.

Additional file 32: Table S29. Gene Ontology analysis of Molecular Function of human homologs of differentially expressed genes at stage C1. Items = Codes of annotations, Items Details = description of annotations, Support $=$ number of genes in input list with a given annotation, List size $=$ number of genes in input list, Reference Support $=$ number of genes in reference list with a given annotation, Reference size $=$ number of genes in reference list, Hyp $=$ Hypergeometric $p$-value, $\operatorname{Hyp} c=$ corrected Hypergeometric p-value (FDR), Genes = genes with given annotation in the input list.

Additional file 33: Table S30. Inter Pro analysis of human homologs of differentially expressed genes at stage $\mathrm{C} 1$. Items $=$ Codes of annotations, Items Details = description of annotations, Support $=$ number of genes in input list with a given annotation, List size $=$ number of genes in input list, Reference Support $=$ number of genes in reference list with a given annotation, Reference size $=$ number of genes in reference list, Hyp = Hypergeometric p-value, Hyp c = corrected Hypergeometric $\mathrm{p}$-value (FDR), Genes = genes with given annotation in the input list.

Additional file 34: Table S31. Gene Ontology analysis (All annotations) of human homologs of differentially expressed genes at stage C2. Items $=$ Codes of annotations, Items Details = description of annotations, 
Support $=$ number of genes in input list with a given annotation, List size $=$ number of genes in input list, Reference Support $=$ number of genes in reference list with a given annotation, Reference size $=$ number of genes in reference list, Hyp = Hypergeometric $p$-value, Hyp c = corrected Hypergeometric p-value (FDR), Genes = genes with given annotation in the input list.

Additional file 35: Table S32. Gene Ontology analysis of Biological Processes of human homologs of differentially expressed genes at stage C2. Items $=$ Codes of annotations, Items Details = description of annotations, Support $=$ number of genes in input list with a given annotation, List size $=$ number of genes in input list, Reference Support = number of genes in reference list with a given annotation, Reference size $=$ number of genes in reference list, $\mathrm{Hyp}=$ Hypergeometric $p$-value, Hyp c = corrected Hypergeometric $p$-value (FDR), Genes = genes with given annotation in the input list.

Additional file 36: Table S33. Gene Ontology analysis of Molecular Function of human homologs of differentially expressed genes at stage C2. Items $=$ Codes of annotations, Items Details $=$ description of annotations, Support = number of genes in input list with a given annotation, List size $=$ number of genes in input list, Reference Support $=$ number of genes in reference list with a given annotation, Reference size $=$ number of genes in reference list, Hyp $=$ Hypergeometric p-value, Hyp c = corrected Hypergeometric p-value (FDR), Genes = genes with given annotation in the input list.

Additional file 37: Table S34. Inter Pro analysis of human homologs of differentially expressed genes at stage C2. Items = Codes of annotations, Items Details = description of annotations, Support = number of genes in input list with a given annotation, List size $=$ number of genes in input list, Reference Support $=$ number of genes in reference list with a given annotation, Reference size $=$ number of genes in reference list, Hyp = Hypergeometric $p$-value, Hyp c = corrected Hypergeometric $p$-value (FDR), Genes = genes with given annotation in the input list.

Additional file 38: Table S35. Gene Ontology analysis (All annotations) of human homologs of differentially expressed genes at stage D. Items = Codes of annotations, Items Details = description of annotations, Support $=$ number of genes in input list with a given annotation, List size $=$ number of genes in input list, Reference Support $=$ number of genes in reference list with a given annotation, Reference size $=$ number of genes in reference list, Hyp $=$ Hypergeometric $p$-value, Hyp c $=$ corrected Hypergeometric $p$-value (FDR), Genes = genes with given annotation in the input list.

Additional file 39: Table S36. Gene Ontology analysis of Biological Processes of human homologs of differentially expressed genes at stage D. Items $=$ Codes of annotations, Items Details $=$ description of annotations, Support = number of genes in input list with a given annotation, List size $=$ number of genes in input list, Reference Support $=$ number of genes in reference list with a given annotation, Reference size $=$ number of genes in reference list, Hyp $=$ Hypergeometric $p$-value, Hyp c $=$ corrected Hypergeometric $p$-value (FDR), Genes = genes with given annotation in the input list.

Additional file 40: Table S37. Gene Ontology analysis of Molecular Function of human homologs of differentially expressed genes at stage D. Items $=$ Codes of annotations, Items Details = description of annotations, Support = number of genes in input list with a given annotation, List size $=$ number of genes in input list, Reference Support = number of genes in reference list with a given annotation, Reference size $=$ number of genes in reference list, Hyp = Hypergeometric $p$-value, Hyp c $=$ corrected Hypergeometric $p$-value (FDR), Genes = genes with given annotation in the input list.

Additional file 41: Table S38. Inter Pro analysis of human homologs of differentially expressed genes at stage D. Items = Codes of annotations, Items Details = description of annotations, Support $=$ number of genes in input list with a given annotation, List size $=$ number of genes in input list, Reference Support $=$ number of genes in reference list with a given annotation, Reference size = number of genes in reference list, Hyp = Hypergeometric $p$-value, Hyp c = corrected Hypergeometric $\mathrm{p}$-value (FDR), Genes = genes with given annotation in the input list.

\section{Competing interests}

The authors declare that they have no competing interests.

\section{Authors' contributions}

DR carried out the RNA isolation, mapping analysis, differential expression analysis, in situ hybridizations and drafted the manuscript. ENS participated in RNA isolation, in situ hybridization and $\mathrm{gPCR}$ analysis. AG, ADL and DAT participated in mapping and differential expression analysis. KF, MRH and MK participated in situ hybridization and maintenance of animals. AWD conceived of the study, and participated in its design and coordination and critically revised the manuscript. All authors read and approved the final manuscript.

\section{Acknowledgments}

The authors would like to acknowledge the Grant Funding NIH R01-AG037699 and the NIR-MCDB Microscopy Facility and the Spectral Laser Scanning Confocal supported by the Office of The Director, National Institutes of Health of the NIH under Award \# S100D010610. We thank Dr. Susannah Kassmer for critical reading of the manuscript and helpful discussions. We thank Amy N. Marten for experiments on the early stages of this project. We would like to thank Mike Caun for his expert care of the De Tomaso laboratory mariculture facility.

\section{Author details}

${ }^{1}$ Department of Molecular, Cellular, and Developmental Biology, University of California, Santa Barbara, Santa Barbara, CA 93106, USA. ²Department of Marine Environmental Biology, University of Southern California, Los Angeles, CA 90089, USA.

Received: 10 July 2014 Accepted: 20 November 2014 Published: 26 December 2014

\section{References}

1. Berrill NJ: The developmental cycle of Botrylloides. Q J Microsc Sci 1947, 88(Pt 4):393-407.

2. Chadwick-Furman NE, Weissman IL: Life history plasticity in chimaeras of the colonial ascidian Botryllus schlosseri. Proc Biol Sci 1995, 262(1364):157-162.

3. Manni L, Zaniolo G, Cima F, Burighel P, Ballarin L: Botryllus schlosseri: a model ascidian for the study of asexual reproduction. Dev Dyn 2007, 236(2):335-352.

4. Tiozzo S, Christiaen L, Deyts C, Manni L, Joly JS, Burighel P: Embryonic versus blastogenetic development in the compound ascidian Botryllus schlosseri: insights from Pitx expression patterns. Dev Dyn 2005, 232(2):468-478.

5. Chadwick-Furman NE, Weissman IL: Life histories and senescence of Botryllus schlosseri (Chordata, Ascidiacea) in Monterey Bay. Biol Bull 1995, 189(1):36-41.

6. Stoner DS, Weissman IL: Somatic and germ cell parasitism in a colonial ascidian: possible role for a highly polymorphic allorecognition system. Proc Natl Acad Sci U S A 1996, 93(26):15254-15259.

7. Tiozzo S, De Tomaso AW: Functional analysis of Pitx during asexual regeneration in a basal chordate. Evol Dev 2009, 11(2):152-162.

8. Sabbadin A: Self- and cross-fertilization in the compound ascidian Botryllus schlosseri. Dev Biol 1971, 24(3):379-391.

9. Zaniolo G, Sabbadin A, Resola C: Dynamics of the colonial cycle in the ascidian, Botryllus schlosseri. The fate of isolated buds. Acta Embryol Exp (Palermo) 1976, 2:205-213.

10. Johnson SL, Yund PO: Remarkable longevity of dilute sperm in a freespawning colonial ascidian. Biol Bull 2004, 206(3):144-151.

11. Mukai $\mathrm{H}$ : Comparative studies on the structure of reproductive organs of four botryllid ascidians. J Morphol 1977, 152(3):363-380.

12. Mukai $\mathrm{H}$, Watanabe $\mathrm{H}$ : Studies on the formation of germ cells in a compound ascidian Botryllus primigenus Oka. J Morphol 1976 148(3):377-362.

13. Sabbadin AaZ G: Sexual Differentiation and Germ Cell Transfer in the Colonial Ascidian Botryllus schlosseri. J Exp Zool 1979, 207:279-301.

14. Manni L, Zaniolo G, Burighel P: Egg Envelop Cytodifferentiation in the Colonial Ascidian Botryllus schlosseri (Tunicata). Acta Zoologica 1993, 74(2):103-113.

15. Manni L, Zaniolo G, Burighel P: An unusual membrane system in the oocyte of the ascidian Botryllus schlosseri. Tissue Cell 1994, 26(3):403-412. 
16. Manni LZ G, Burighel P: Ultrastructural Study of Oogenesis in the Compound Ascidian Botryllus schlosseri (Tunicata). Acta Zoologica 1994, 75(2):101-113

17. Voskoboynik A, Neff NF, Sahoo D, Newman AM, Pushkarev D, Koh W, Passarelli B, Fan HC, Mantalas GL, Palmeri K, Ishizuka KJ, Gissi C, Griggio F, Ben-Shlomo R, Corey DM, Penland L, White RA, Weissman IL, Quake SR: The genome sequence of the colonial chordate, Botryllus schlosseri. Elife 2013, 2:e00569.

18. Anders S, Huber W: Differential expression analysis for sequence count data. Genome Biol 2010, 11(10):R106.

19. Brown FD, Tiozzo S, Roux MM, Ishizuka K, Swalla BJ, De Tomaso AW: Early lineage specification of long-lived germline precursors in the colonial ascidian Botryllus schlosseri. Development 2009, 136(20):3485-3494.

20. Kawamura K, Sunanaga T: Role of Vasa, Piwi, and Myc-expressing coelomic cells in gonad regeneration of the colonial tunicate, Botryllus primigenus. Mech Dev 2011, 128(7-10):457-470.

21. Rinkevich Y, Voskoboynik A, Rosner A, Rabinowitz C, Paz G, Oren M, Douek J, Alfassi G, Moiseeva E, Ishizuka KJ, Palmeri KJ, Weissman IL, Rinkevich B: Repeated, long-term cycling of putative stem cells between niches in a basal chordate. Dev Cell 2013, 24(1):76-88.

22. Rosner A, Moiseeva E, Rabinowitz C, Rinkevich B: Germ lineage properties in the urochordate Botryllus schlosseri - from markers to temporal niches. Dev Biol 2013, 384(2):356-374

23. Sunanaga $\mathrm{T}$, Inubushi H, Kawamura K: Piwi-expressing hemoblasts serve as germline stem cells during postembryonic germ cell specification in colonial ascidian, Botryllus primigenus. Dev Growth Differ 2010, 52(7):603-614.

24. Bucko-Justyna M, Lipinski L, Burgering BM, Trzeciak L: Characterization of testis-specific serine-threonine kinase 3 and its activation by phosphoinositide-dependent kinase-1-dependent signalling. FEBS J 2005, 272(24):6310-6323.

25. Toshima J, Koji T, Mizuno K: Stage-specific expression of testis-specific protein kinase 1 (TESK1) in rat spermatogenic cells. Biochem Biophys Res Commun 1998, 249(1):107-112.

26. Hofmann O, Caballero OL, Stevenson BJ, Chen YT, Cohen T, Chua R, Maher CA, Panji S, Schaefer U, Kruger A, Lehvaslaiho M, Carninci P, Hayashizaki $Y$, Jongeneel CV, Simpson AJ, Old LJ, Hide W: Genome-wide analysis of cancer/ testis gene expression. Proc Natl Acad Sci U S A 2008, 105(51):20422-20427.

27. Sutovsky P: Sperm proteasome and fertilization. Reproduction 2011, 142(1):1-14.

28. Tres $L L$, Kierszenbaum AL: The ADAM-integrin-tetraspanin complex in fetal and postnatal testicular cords. Birth Defects Res C Embryo Today 2005, 75(2):130-141

29. Schneider WJ: Vitellogenin receptors: oocyte-specific members of the low-density lipoprotein receptor supergene family. Int Rev Cytol 1996, 166:103-137.

30. Akasaka M, Kato KH, Kitajima K, Sawada H: Identification of novel isoforms of vitellogenin expressed in ascidian eggs. J Exp Zool B Mol Dev Evol 2013, 320(2):118-128

31. Sawada H, Sakai N, Abe Y, Tanaka E, Takahashi Y, Fujino J, Kodama E, Takizawa S, Yokosawa H: Extracellular ubiquitination and proteasomemediated degradation of the ascidian sperm receptor. Proc Natl Acad SCi U S A 2002, 99(3):1223-1228.

32. Kurn U, Sommer F, Bosch TC, Khalturin K: In the urochordate Ciona intestinalis zona pellucida domain proteins vary among individuals. Dev Comp Immunol 2007, 31(12):1242-1254.

33. Mengerink KJ, Vacquier VD: Glycobiology of sperm-egg interactions in deuterostomes. Glycobiology 2001, 11(4):37R-43R.

34. Ohnishi J, Ohnishi E, Shibuya H, Takahashi T: Functions for proteinases in the ovulatory process. Biochim Biophys Acta 2005, 1751(1):95-109.

35. Napoli JL: 17beta-Hydroxysteroid dehydrogenase type 9 and other short-chain dehydrogenases/reductases that catalyze retinoid, 17beta- and 3alpha-hydroxysteroid metabolism. Mol Cell Endocrinol 2001, 171(1-2):103-109.

36. Fusi FM, Montesano M, Bernocchi N, Panzeri C, Ferrara F, Villa A, Bronson RA: P-selectin is expressed on the oolemma of human and hamster oocytes following sperm adhesion and is also detected on the equatorial region of acrosome-reacted human spermatozoa. Mol Hum Reprod 1996, 2(5):341-347.

37. Geng JG, Raub TJ, Baker CA, Sawada GA, Ma L, Elhammer AP: Expression of a P-selectin ligand in zona pellucida of porcine oocytes and P-selectin on acrosomal membrane of porcine sperm cells. Potential implications for their involvement in sperm-egg interactions. J Cell Biol 1997, 137 (3):743-754
38. Oehninger S, Patankar M, Seppala M, Clark GF: Involvement of selectin-like carbohydrate binding specificity in human gamete interaction. Andrologia 1998, 30(4-5):269-274

39. Carmona-Saez P, Chagoyen M, Tirado F, Carazo JM, Pascual-Montano A: GENECODIS: a web-based tool for finding significant concurrent annotations in gene lists. Genome Biol 2007, 8(1):R3.

40. Nogales-Cadenas R, Carmona-Saez P, Vazquez M, Vicente C, Yang X, Tirado F, Carazo JM, Pascual-Montano A: GeneCodis: interpreting gene lists through enrichment analysis and integration of diverse biological information. Nucleic Acids Res 2009, 37(Web Server issue):W317-W322.

41. Tabas-Madrid D, Nogales-Cadenas R, Pascual-Montano A: GeneCodis3: a non-redundant and modular enrichment analysis tool for functional genomics. Nucleic Acids Res 2012, 40(Web Server issue):W478-W483.

42. Babin PJ: Apolipoproteins and the association of egg yolk proteins with plasma high density lipoproteins after ovulation and follicular atresia in the rainbow trout (Salmo gairdneri). J Biol Chem 1987, 262(9):4290-4296.

43. Fujimoto VY, Kane JP, Ishida BY, Bloom MS, Browne RW: High-density lipoprotein metabolism and the human embryo. Hum Reprod Update 2010, 16(1):20-38.

44. Walzem RL, Hansen RJ, Williams DL, Hamilton RL: Estrogen induction of VLDLy assembly in egg-laying hens. J Nutr 1999, 129(2S Suppl):467S-472S.

45. Boyd HC, Brown SK, Harpi JA, Weissmanz IL: Growth and Sexual Maturation of Laboratory Cultured Monterey Botryllus Schlosseri. Biol Bull 1986, 170:91-109.

46. Lauzon RJ, Rinkevich B, Patton CW, Weissman IL: A morphological study of nonrandom senescence in a colonial urochordate. Biol Bull 2000, 198 (3):367-378.

47. McKitrick TR, Muscat CC, Pierce JD, Bhattacharya D, De Tomaso AW: Allorecognition in a basal chordate consists of independent activating and inhibitory pathways. Immunity 2011, 34(4):616-626.

48. Barrett T, Wilhite SE, Ledoux P, Evangelista C, Kim IF, Tomashevsky M, Marshall KA, Phillippy KH, Sherman PM, Holko M, Yefanov A, Lee H, Zhang N, Robertson CL, Serova N, Davis S, Soboleva A: NCBI GEO: archive for functional genomics data sets-update. Nucleic Acids Res 2013, 41 (Database issue):D991-D995.

49. Edgar R, Domrachev M, Lash AE: Gene Expression Omnibus: NCBI gene expression and hybridization array data repository. Nucleic Acids Res 2002, 30(1):207-210.

50. Langmead B, Trapnell C, Pop M, Salzberg SL: Ultrafast and memoryefficient alignment of short DNA sequences to the human genome. Genome Biol 2009, 10(3):R25.

51. Lapatsina L, Brand J, Poole K, Daumke O, Lewin GR: Stomatin-domain proteins. Eur J Cell Biol 2012, 91(4):240-245.

52. Yang MH, Su JZ, Liu J, Li YH: Cloning and expression of Tssk1 \& Tssk2 in mice and the presence $\&$ localization of them in mature sperm. Dongwuxue Yanjiu 2012, 33(4):381-388.

53. Kasamatsu S, Hachiya A, Fujimura T, Sriwiriyanont $P$, Haketa K, Visscher MO, Kitzmiller WJ, Bello A, Kitahara T, Kobinger GP, et al: Essential role of microfibrillar-associated protein 4 in human cutaneous homeostasis and in its photoprotection. Sci Rep 2011, 1:164.

54. Xue F, Cooley L: kelch encodes a component of intercellular bridges in Drosophila egg chambers. Cell 1993, 72(5):681-693.

55. Carrell DT: Epigenetics of the male gamete. Fertil Steril 2012, 97(2):267-274.

56. Richard I, Devaud C, Cherif D, Cohen D, Beckmann JS: The gene for creatine kinase, mitochondrial 2 (sarcomeric; CKMT2), maps to chromosome 5q13.3. Genomics 1993, 18(1):134-136.

57. Toshima J, Nakagawara K, Mori M, Noda T, Mizuno K: Structural organization and chromosomal localization of the mouse tesk1 (testisspecific protein kinase 1) gene. Gene 1998, 206(2):237-245

58. Yamaguchi S, Yamane T, Takahashi-Niki K, Kato I, Niki T, Goldberg MS, Shen J, Ishimoto K, Doi T, Iguchi-Ariga SM, et al: Transcriptional activation of low-density lipoprotein receptor gene by DJ-1 and effect of DJ-1 on cholesterol homeostasis. PLOS One 2012, 7(5):e38144.

59. Herlyn $\mathrm{H}$, Zischler $\mathrm{H}$ : The molecular evolution of sperm zonadhesin. Int J Dev Biol 2008, 52(5-6):781-790.

60. Wang S, Zheng H, Esaki Y, Kelly F, Yan W: Cullin3 is a KLHL10-interacting protein preferentially expressed during late spermiogenesis. Biol Reprod 2006, 74(1):102-108.

61. Hartong DT, Dange M, McGee TL, Berson EL, Dryja TP, Colman RF: Insights from retinitis pigmentosa into the roles of isocitrate dehydrogenases in the Krebs cycle. Nat Genet 2008, 40(10):1230-1234. 
62. Govindaraju A, Dogan S, Rodriguez-Osorio N, Grant K, Kaya A, Memili E: Delivering value from sperm proteomics for fertility. Cell Tissue Res 2012, 349(3):783-793.

63. Tanigawa M, Miyamoto K, Kobayashi S, Sato M, Akutsu H, Okabe M, Mekada E, Sakakibara K, Miyado M, Umezawa A, et al: Possible involvement of CD81 in acrosome reaction of sperm in mice. Mol Reprod Dev 2008, 75(1):150-155.

64. Edwards DR, Handsley MM, Pennington CJ: The ADAM metalloproteinases. Mol Aspects Med 2008, 29(5):258-289.

65. Zhong JL, Poghosyan Z, Pennington CJ, Scott X, Handsley MM, Warn A, Gavrilovic J, Honert K, Kruger A, Span PN, et al: Distinct functions of natural ADAM-15 cytoplasmic domain variants in human mammary carcinoma. Mol Cancer Res 2008, 6(3):383-394.

66. Costache V, McDougall A, Dumollard R: Cell cycle arrest and activation of development in marine invertebrate deuterostomes. Biochem Biophys Res Commun 2014.

67. Lum L, Blobel CP: Evidence for distinct serine protease activities with a potential role in processing the sperm protein fertilin. Dev Biol 1997 191(1):131-145.

68. Brown PR, Miki K, Harper DB, Eddy EM: A-kinase anchoring protein 4 binding proteins in the fibrous sheath of the sperm flagellum. Biol Reprod 2003, 68(6):2241-2248.

69. Vogel BE, Hedgecock EM: Hemicentin, a conserved extracellular member of the immunoglobulin superfamily, organizes epithelial and other cell attachments into oriented line-shaped junctions. Development 2001, 128(6):883-894.

70. Spiridonov NA, Wong L, Zerfas PM, Starost MF, Pack SD, Paweletz CP, Johnson GR: Identification and characterization of SSTK, a serine/ threonine protein kinase essential for male fertility. Mol Cell Biol 2005, 25(10):4250-4261.

71. Kurahashi H, Taniguchi M, Meno C, Taniguchi Y, Takeda S, Horie M, Otani H, Toda T: Basement membrane fragility underlies embryonic lethality in fukutin-null mice. Neurobiol Dis 2005, 19(1-2):208-217.

72. Ricardo S, Lehmann R: An ABC transporter controls export of a Drosophila germ cell attractant. Science 2009, 323(5916):943-946.

73. Konno A, Setou M, Ikegami K: Ciliary and flagellar structure and functiontheir regulations by posttranslational modifications of axonemal tubulin. Int Rev Cell Mol Biol 2012, 294:133-170.

74. Milisav I, Jones MH, Affara NA: Characterization of a novel human dyneinrelated gene that is specifically expressed in testis. Mamm Genome 1996, 7(9):667-672.

75. Wiesner B, Weiner J, Middendorff R, Hagen V, Kaupp UB, Weyand I: Cyclic nucleotide-gated channels on the flagellum control $\mathrm{Ca} 2+$ entry into sperm. J Cell Biol 1998, 142(2):473-484.

doi:10.1186/1471-2164-15-1183

Cite this article as: Rodriguez et al: Analysis of the basal chordate Botryllus schlosseri reveals a set of genes associated with fertility. BMC Genomics 2014 15:1183.

\section{Submit your next manuscript to BioMed Central and take full advantage of:}

- Convenient online submission

- Thorough peer review

- No space constraints or color figure charges

- Immediate publication on acceptance

- Inclusion in PubMed, CAS, Scopus and Google Scholar

- Research which is freely available for redistribution

Submit your manuscript at www.biomedcentral.com/submit

C BioMed Central 